\title{
El Pucará de Aconquija "que llaman del Inga» y el pueblo de los Malle en la frontera sudoriental del Tawantinsuyu
}

\section{The Pucará of Aconquija «Which They Call the Ingas» and the People of Malle in the Southeastern Frontier of Tawantinsuyu}

CLAUDIO JAVIER PATANÉ ARÁOZ

Universidad Nacional de Córdoba

patanearaoz@yahoo.com

\section{RESUMEN}

El análisis de los diferentes matices que adquiriera la conquista inca en el sur de los Andes recibe permanente atención tanto de arqueólogos como de historiadores. Recientes estudios efectuados en diferentes regiones del Collasuyu evaluaron las relaciones existentes entre las politicas expansivas, los sistemas de defensa y la interacción étnica en contextos de frontera. Como consecuencia, se generaron prometedoras áreas de debate. En este trabajo presento los resultados de investigaciones arqueológicas y análisis de fuentes históricas relacionadas con el Pucará de Aconquija (Catamarca, Argentina). Este sitio es una de las más importantes fortalezas incas desplegadas en la frontera sudoriental del Tawantinsuyu. Palabras clave: Pucará de Aconquija, Inca, Malle, fronteras, fortalezas

\section{ABSTRACT}

The analysis of the nuances of the Inca conquest in the southern Andes has received consistent attention from both archaeologists and historians. Recent studies carried out in different regions of Collasuyu have evaluated the relationship between expansionary policies, systems of defense, and ethnic interaction in borderland contexts. These studies have generated promising areas of debate.

HISTORIOA XLI.2 (2017): 7-55 / ISSN 0252-8894

https://doi.org/10.18800/historica.201702.001 
In this paper I present results of archaeological studies and analysis of historical sources related to the Pucara of Aconquija (Catamarca, Argentina). This site is one of the most important Inca fortresses located on the southeastern frontier of Tawantinsuyu.

Keywords: Pucará de Aconquija, Inca, Malle, frontiers, fortress

n las últimas décadas, un importante conjunto de estudios en
numerosas regiones de los Andes se dedicó a evaluar las relaciones existentes entre las políticas expansionistas del imperio inca, sus sistemas de defensa y las dinámicas sociales interétnicas en contextos de frontera. ${ }^{1}$ Estos renovados esfuerzos generaron significativos avances que se insertaron directamente dentro de campos de debate ya establecidos. ${ }^{2}$ De esta manera, aunque no sin dificultades, se hacía evidente que la complementación interdisciplinaria entre la historia y la arqueología estimulaba la continua retroalimentación emergente de múltiples interrogantes de investigación y la práctica de estudios más abarcadores.

La necesidad de emplear una línea de investigación interdisciplinaria en los estudios sobre las fortalezas y fronteras del Tawantinsuyu había sido señalada enfáticamente tiempo atrás por el arqueólogo John Hyslop:

El incremento en el uso de las fuentes históricas tempranas, administrativas y legales, así como una evaluación más crítica de los cronistas "clásicos», ha permitido a los entendidos discutir la expansión del imperio como una sucesión de etapas durante los reinados de determinados emperadores [...]. Es posible que este importante enfoque del estudio de las fronteras incas despierte un nuevo interés en el crecimiento del estado inca. Es importante que la evidencia arqueológica sea usada en coordinación con la investigación etnohistórica, ya que las instalaciones militares incas, ubicadas dentro de los límites extremos del imperio pueden arrojar evidencia sobre las más antiguas fronteras, anteriores a la subsiguiente expansión del estado. ${ }^{3}$

1 Véase, por ejemplo, Alconini 2004, Caillavet 1985, Cremonte y Garay de Fumagalli 2013, Pärssinen y Siiriäinen 2003, y Schjellerup 1998.

2 Dillehay y Netherly 1998: 275; y Raffino y Stehberg 1999.

3 Hyslop 1988: 45. 
Así, desde un marco general, las particularidades que caracterizaron al último proceso imperial prehispánico en el noroeste de Argentina [en adelante NOA] han sido objeto de continuo interés para la arqueología y la historia. ${ }^{4}$ De hecho, recientes investigaciones han apelado al uso complementario de fuentes históricas y arqueológicas para lograr metas conjuntas. Ello implicó promover un mayor interés por el estudio de las prácticas y articulaciones de los grupos locales anexados al imperio; es decir, agudizar los lineamientos metodológicos empleados en el análisis de las prestaciones indígenas a los cusqueños y sus respuestas a esa situación de conquista y dominio. ${ }^{5}$ Sin embargo, a pesar de estos renovados intereses de estudio, el análisis interdisciplinario sobre las fortalezas y sus habitantes en el contexto de fronteras incas no ha recibido aún suficiente atención.

En ese sentido, el objetivo general de este trabajo es, a través de un caso de estudio, contribuir en esa dirección. Me ocuparé aquí del análisis de una de las más grandes y complejas fortalezas prehispánicas construidas por los incas en su frontera sudoriental: el Pucará de Aconquija. Este sitio se dio a conocer en la literatura especializada a mediados del siglo XIX y, desde entonces, se le otorgó gran importancia. Sin embargo, hasta ahora solo se han efectuado escasos registros de algunos indicadores superficiales que se asociaron de manera automática al periodo de dominio inca - típica arquitectura imperial de las provincias y escasos fragmentos cerámicos con estilos que se atribuyeron a poblaciones mitmaqkuna-; por lo que, ante la ausencia de investigaciones más profundas y minuciosas, esas evidencias superficiales fueron suficientes para que otros investigadores formularan un conjunto de hipótesis sobre aspectos funcionales y de rangos temporales de ocupación. Así, se sostuvo que el Pucará de Aconquija fue construido por mandato de los Incas y ocupado por poblaciones trasladadas durante un breve periodo muy cercano a la caída del

4 Algunos destacados ejemplos relativos al análisis de fuentes históricas, complementados con investigaciones arqueológicas realizadas en Argentina, pueden ser consultados en González 1982 y Lorandi 1980.

5 Véanse, por ejemplo, Lorandi y Boixadós 1987-1988; Williams y Cremonte. 19921993; y Zanolli 2003. 
Tawantinsuyu. Como consecuencia, se le asignó al Pucará una función exclusivamente militar: la de defender los territorios conquistados de las excursiones depredadoras de peligrosos grupos nómades del este. Desafortunadamente, ni arqueólogos ni etnohistoriadores prestaron mayor atención a las informaciones derivadas del análisis de fuentes históricas relacionadas a este asentamiento prehispánico y a sus habitantes.

A fin de revertir estos sesgos en las investigaciones, venimos estudiando el Pucará de Aconquija en el marco de un proyecto de investigación interdisciplinario bajo mi dirección desde el año 2009. En este ensayo presentaré y evaluaré, en primer lugar, los resultados del trabajo arqueológico de campo y de los análisis de materiales en el laboratorio. Dichos análisis, además de permitirme discutir las hipótesis planteadas anteriormente, ofrecen nuevos datos que serán útiles para comenzar a reconstruir otros aspectos de la «biografía» de ese sitio. En segundo lugar, se presentará el análisis de diversas fuentes históricas de la época colonial —elaboradas entre los siglos XVI al XVIII- que aluden directa o indirectamente al Pucará y a sus habitantes. Entre dichas fuentes, tuvo marcada relevancia un documento fechado en el año 1626 que refiere a la confirmación de la entrega de una merced al capitán Sebastián de Loria en «la Estancia y tierras del Pucara de Anconquija, y Pampa de la Sierra». Ese documento revela la presencia de un "Pucará que llaman del Inga» en estas tierras y, a su vez, menciona al "pueblo de Malle» localizado en cercanía a ese Pucará. ${ }^{6}$ De acuerdo con el marco propuesto, en este trabajo partiré de la hipótesis de que el Pucará de Aconquija es el mismo que en la merced citada se alude como «del Inga» y que el referido pueblo «Malle» habría sido una población traslada por los Incas a la zona en calidad de mitmaqkuna.

\section{EL PUCARÁ DE ACONQUIJA: PRESENTACIÓN}

Este sitio arqueológico, conocido también como Fuerte de Andalgalá, Pucará de Ambato o Ruinas del Pucará, comenzó a adquirir paulatina notoriedad entre los asentamientos prehispánicos del NOA a

6 Archivo Histórico de Catamarca, Causa Civil, Sección Judicial, Caja n. ${ }^{\circ}$ 1, Expediente n. ${ }^{\circ} 22.746$. 
partir de pioneros trabajos publicados entre mediados del siglo XIX y principios del siglo XX. ${ }^{7}$ Los arqueólogos del mundo andino interesados en las secuelas de las conquistas incaicas en sus provincias señalan que este asentamiento es una de las evidencias materiales más notorias de la presencia y dominio inca en Argentina, además de una de las fortificaciones más complejas y significativas dentro del entramado defensivo de la frontera sudoriental del Tawantinsuyu. ${ }^{8}$ A continuación, se presentan sus principales características.

El Pucará de Aconquija se localiza en el distrito Aconquija, porción sureste del departamento Andalgalá, provincia de Catamarca. De forma más específica, se encuentra en la región del bolsón de Andalgalá, un área que al momento de la conquista incaica se encontraba ocupada por poblaciones Diaguitas. De acuerdo con lo establecido para las delimitaciones de lo que fueron las provincias incas en el NOA, este sitio se ubicó dentro de la provincia de Quire-Quire, una porción del cuadrante sudoriental del imperio: el Collasuyu. ${ }^{9}$ En el bolsón de Andalgalá se registraron otros importantes asentamientos incaicos conectados por tramos del qhapaq ñan. ${ }^{10}$ A partir de una caracterización funcional, esos sitios fueron identificados como centros administrativos (Potrero Chaquiago), tambos (Portezuelo, Huehuel, Campo Colorado, Ingenio del Arenal Médanos, Humaya 4), fortalezas (Nevados del Aconquija, o Pucará de las Pavas), áreas agrícolas (Carapunko), qhapac ñan y zona de enterratorio (Agua Verde, ubicada cerca de Potrero Chaquiago); véase la figura 1. Por otro lado, los fechados obtenidos en Potrero Chaquiago y Agua Verde permitieron establecer que la región fue incorporada al Collasuyu entre finales del siglo XIV y comienzos del siglo XV, y que

7 Los primeros estudios que hicieron referencia específica al Pucará de Aconquija fueron Tschudi 1966; Lange 1892; y Bruch 1913: 175-187.

8 La notoriedad de este sitio fue destacada por numerosos investigadores en Argentina; véanse, por ejemplo, González 1982: 334; Kriscautzky 2002-2004: 168; y Raffino 2007: 315. En el contexto general del Collasuyu se puede consultar D'Altroy 2003: 253-255; y Hyslop 1990: 182-190. Este sitio fue declarado Monumento Histórico Nacional de la República Argentina mediante Decreto del Poder Ejecutivo N. ${ }^{\circ}$ 1145/97.

9 González 1982: 332.

${ }^{10}$ Williams 2000. 


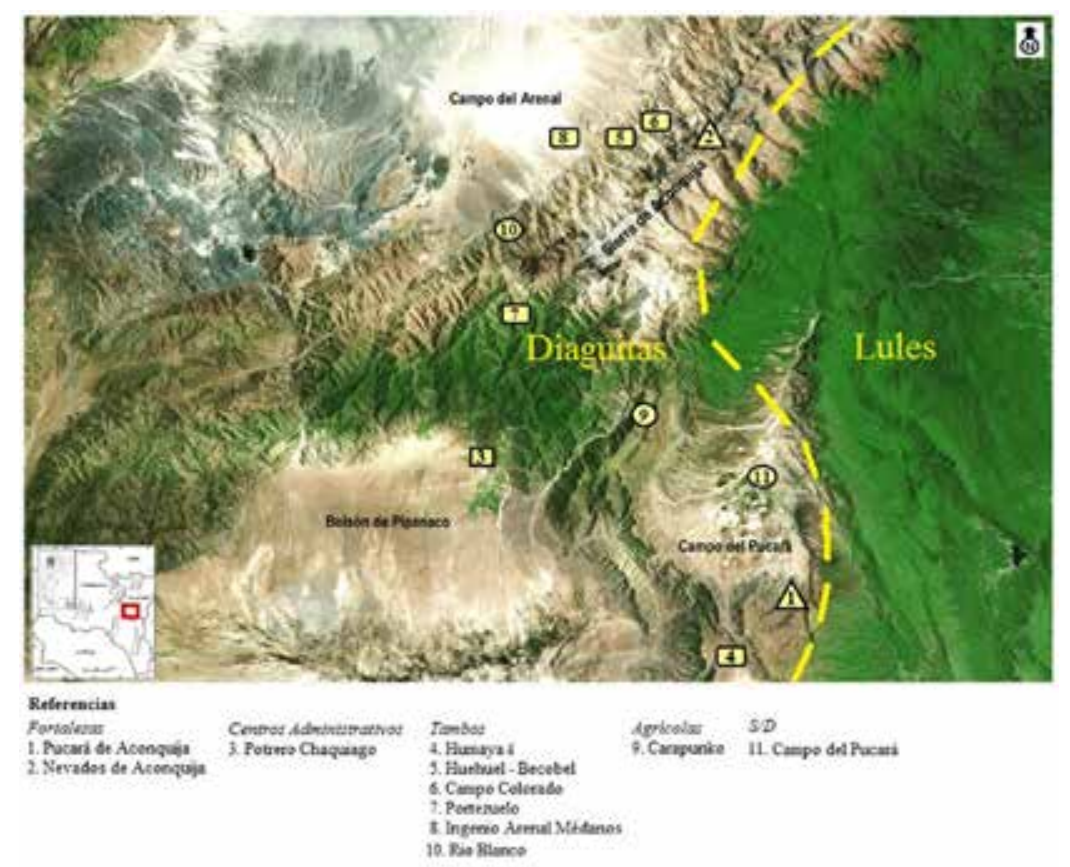

Figura 1. Imagen satelital de la región del bolsón de Andalgalá con los sitios incas mencionados en el cuerpo del texto. Se señala con una hilera demarcatoria la ocupación espacial de las poblaciones Diaguitas y Lules. «S/D» (sin datos) se refiere a evidencias incaicas reportadas de forma muy sintética. Elaboración propia.

tácticas de la política imperial de características intensivas se aplicaron en bolsones o islas productivas estratégicamente ubicadas. ${ }^{11}$

En esos sitios incas del bolsón de Andalgalá se registraron principalmente conjuntos cerámicos de estilos alóctonos, manufacturados por grupos étnicos aliados a los incas y originarios de la franja fronteriza oriental (llanuras tucumano-santiagueñas, del territorio Lule-Tonocoté; estilos: Famabalasto negro sobre rojo y Yocavil), del extremo norte de Argentina y del sur de Bolivia (estilo: Yavi Chico policromo). De acuerdo con estos registros, la ocupación incaica al interior del área valliserrana de la provincia de Catamarca debió estar delegada principalmente a

${ }^{11}$ Williams y D’Altroy 1998: 175-177. 
poblaciones relocalizadas con el objetivo de controlar a las poblaciones locales (Diaguitas), producir determinados bienes y proteger los espacios de la frontera imperial contra las incursiones de las poblaciones nómades del área chaqueña (Lules). ${ }^{12}$

El Pucará de Aconquija se encuentra emplazado sobre una amplia y relativamente llana cima en la porción distal de una angosta quebrada que forma parte del extremo meridional de la sierra de Ambato, dentro de las estribaciones montañosas de las sierras de Narváez y Las Carretas (figura 3.A). ${ }^{13} \mathrm{Al}$ pie del Pucará, se sitúa una pequeña población llamada El Pucará y un río de bajo caudal y de régimen permanente del mismo nombre. El sitio arqueológico se despliega a unos 250 metros por encima del poblado y se accede a él a través de las sendas utilizadas principalmente por los pobladores locales y los turistas ocasionales. El ascenso es ciertamente dificultoso y requiere de mucho tiempo debido a lo abrupto de las pendientes del cerro. Desde lo paisajístico, este lugar ofrece una inmejorable visión de la extensa depresión tectónica conocida como el Campo del Pucará, ubicada a corta distancia en dirección al norte. ${ }^{14}$ Esta depresión conforma una espaciosa llanura de una extensión cercana a los 23 kilómetros de largo y 10 kilómetros de ancho, y se encuentra rodeada por cadenas montańosas de gran altura: por el norte, la sierra de Aconquija (5400 m.s.n.m.); por el sur, la cadena del Manchao (4050 m.s.n.m.); y por el oeste, las sierras de Narváez.

Los relevamientos previos efectuados en el sitio destacaron la monumentalidad arquitectónica del lugar. Precisamente, en el extenso y pormenorizado análisis de John Hyslop sobre la variabilidad de asentamientos militares incaicos desplegados en su imperio, se distinguió al Pucará de

\footnotetext{
${ }^{12}$ Lorandi 1983; y 1980: 158-163.

${ }^{13}$ El Pucará de Aconquija se ubica a una cota altitudinal de 2110 m.s.n.m., coordenadas geográficas S27042’30”- O6559'51”.

${ }^{14}$ El Campo del Pucará fue investigado sistemáticamente desde la pasada década de 1950. Los resultados alcanzados aportaron valiosos datos principalmente relacionados con la ocupación local durante el periodo Formativo ("Cultura Alamito»); véase Núñez Regueiro 1998. Las evidencias incas registradas en el Campo del Pucará fueron muy escasas; véase Gianfrancisco 2014: 161.
} 
Aconquija como una de las más complejas y sofisticadas fortalezas. ${ }^{15}$ Este Pucará ocupa un área aproximada de 2000 metros en sentido norte-sur y un ancho cercano a los 1000 metros en sentido este-oeste. Las modalidades arquitectónicas y el patrón general del asentamiento reflejan rasgos netamente incaicos, con recintos destinados a diversas funciones: residenciales, públicas, de almacenamiento y defensivas (kanchas, kallankas, qollqas, hornacinas, muros trapezoidales, murallas con refuerzo, troneras, torreones, banquetas). La organización edilicia fue establecida en dos sectores (sur y norte) claramente diferenciados y separados por una distancia aproximada de 650 metros (figura 2). El sector sur es manifiestamente el de mayor variabilidad arquitectónica y densidad edilicia, y se encuentra dividido espacialmente en dos subsectores. Esta planificación estructural pudo haber respondido a las subdivisiones socio-espaciales o dualidades simbólicas de los incas (como el hanan y el hurin), que imitaban y reproducían las características físicas y paisajísticas del Cusco en las provincias. ${ }^{16}$

Otra de las más notorias características arquitectónicas del sitio son los casi 3000 metros de murallas defensivas perimetrales que, en algunos sectores, presentan entre dos y cuatro metros de altura (véase figura 3.B). Esas elaboradas murallas fueron instaladas en posiciones estratégicas para velar los flancos débiles del terreno y defender los dos grandes núcleos residenciales. En algunos sectores, se registraron escalones longitudinales (banquetas) que habrían permitido el desplazamiento de personas a cubierto y la posibilidad de observar hacia el exterior (figura 3.D). Además, estas murallas cuentan con troneras y saeteras desde donde se pudieron arrojar elementos defensivos. Asimismo, ciertas características constructivas de las murallas remiten a diferentes grupos étnicos que, de acuerdo con el régimen de trabajo rotativo o mit'a, habrían participado en su construcción. ${ }^{17}$

\footnotetext{
${ }^{15}$ Hyslop 1990: 182-190.

${ }^{16}$ Ib.: 184.

${ }^{17}$ Kriscautzky 2002-2004: 170-174.
} 


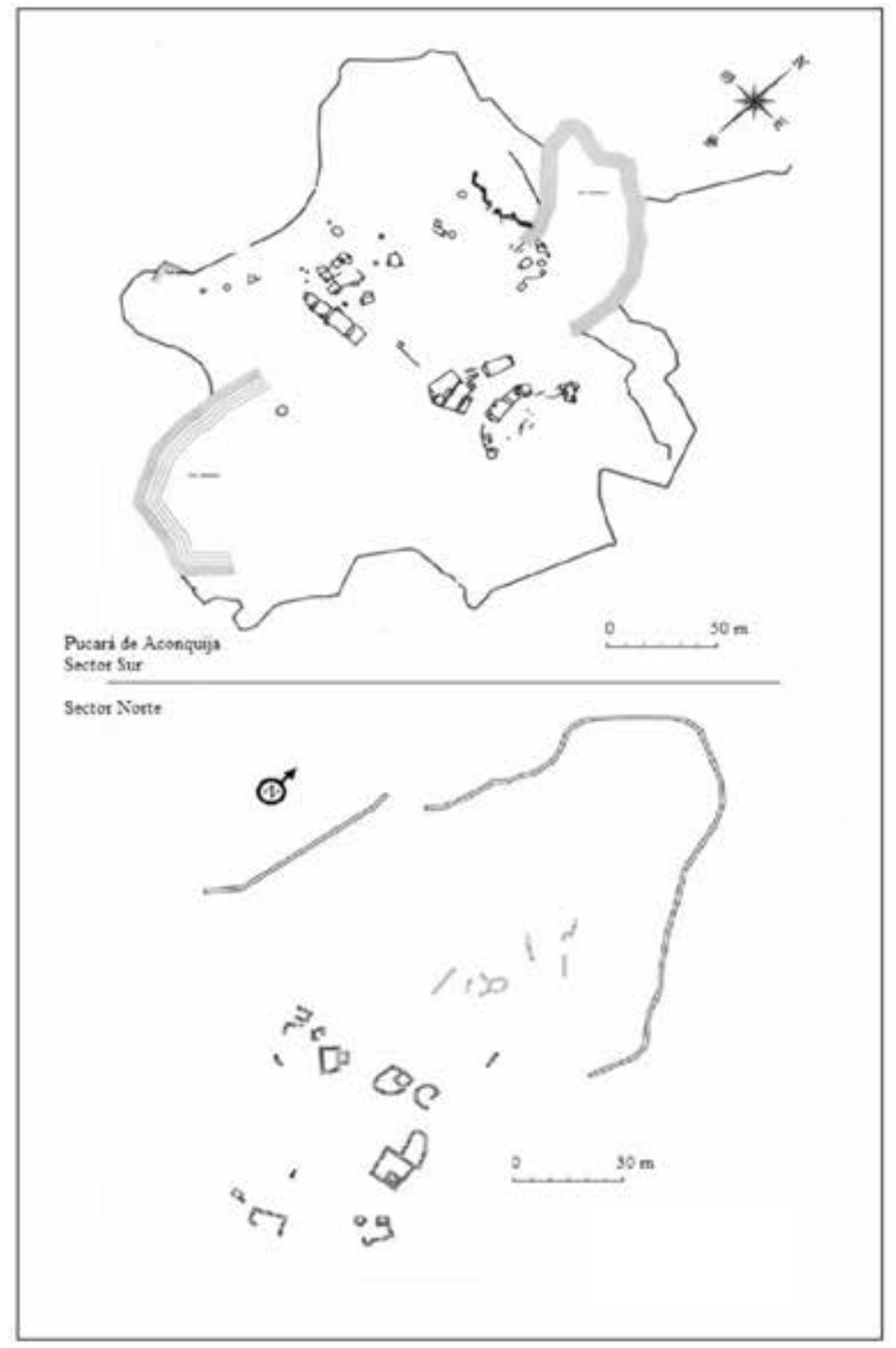

Figura 2. Planos de los sectores sur y norte del Pucará de Aconquija. Elaborados por Ratto (2000). 

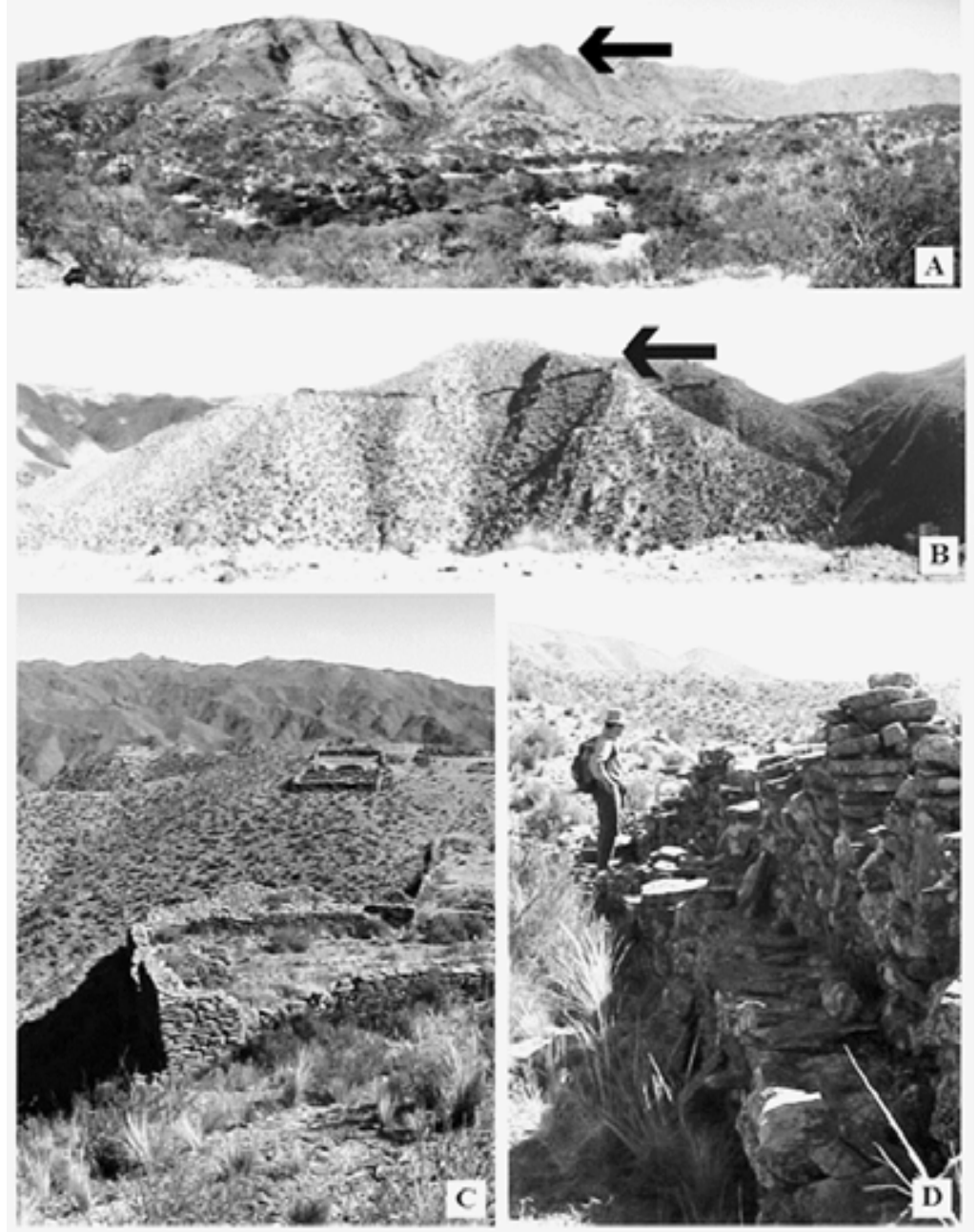

Figura 3. El Pucará de Aconquija. (3.A) Imagen panorámica de la ubicación del Pucará de Aconquija, desde el oeste; (3.B) un tramo de las murallas hacia el este del sitio; (3.C) recintos del sector sur; y (3.D) una fracción de las murallas con refuerzos (banquetas). Fotografías y elaboración propias. 
También es muy necesario señalar que, pocos años atrás, se registró un importante tramo del qhapac ñan que vincula al Pucará de Aconquija con El Bajo, un sitio de reducidas dimensiones ubicado al pie del cerro. Este trayecto de 873 metros se localiza en la ladera occidental de la quebrada de la Chilca, presenta un ancho variable (entre 0,8 y 4 metros) y se encuentra actualmente en muy buen estado de conservación. Asociada a ese tramo del camino inca se encuentra una gran roca de forma piramidal y de alta visibilidad que los investigadores identificaron como una wank'a. ${ }^{18}$ Este segmento del qhapac ñan fue declarado recientemente «Patrimonio Cultural de la Humanidad», como parte del conjunto de propuestas elevadas por la República Argentina.

\section{INVESTIGACIONES E HIPÓTESIS PREVIAS}

Como mencioné anteriormente, los conocimientos actuales sobre el Pucará se basan únicamente en breves relevamientos de la arquitectura del sitio y el reconocimiento de pocos fragmentos cerámicos en superficie. ${ }^{19}$ Pese a ello, algunos investigadores han llegado a formular un variado conjunto de hipótesis relacionadas con aspectos funcionales y de temporalidad en la ocupación del sitio. Esas hipótesis pueden ser sintetizadas de la siguiente manera:

- Funcional: Por su localización en lo alto de un cerro, por su difícil acceso y en conjunción con la construcción de dispositivos arquitectónicos de corte estrictamente defensivo, se le confirió al Pucará de Aconquija una funcionalidad de tipo "fortaleza militar». Asimismo, se le asignó un rol ligado al control de tráfico humano por su localización en un punto geográfico clave. ${ }^{20}$

${ }^{18}$ Orgaz, Kriscautzky y Caletti 2007.

${ }^{19}$ Debe señalarse que se cuenta con un registro de excavaciones en el sitio (sondeos preliminares) que fue comentado de forma muy somera en una publicación; véase González 1982: 335; y 2000: 160 .

${ }^{20}$ D'Altroy 2003: 255; Hyslop 1990: 186; Kriscautzky 2002-2004: 168; Lafone Quevedo 1888: 4; Lorandi 1983: 18-19; y Williams 2000: 67. 
- El Pucará en el contexto de fronteras incaicas en la región: Durante el periodo previo a la conquista incaica, conocido como Tardío o de Desarrollos Regionales (c. 900-1420), amplias regiones del NOA se vieron envueltas dentro de una prolongada etapa de complejización sociopolítica, crecimiento demográfico y acentuación en la beligerancia interna. ${ }^{21}$ Fueron tiempos marcados por valerosos y bien adiestrados guerreros y la proliferación de asentamientos fortificados ubicados en lo alto de cerros. ${ }^{22}$ Los grupos sociales que durante ese periodo ocuparon la región comprendida entre los valles Calchaquí y de Santa María formaron una gran unidad étnica y lingüística - de habla kakana - que fue englobada por los españoles bajo el rótulo étnico de Diaguitas. La reconocida investigadora Ana Lorandi propuso, sobre la base de análisis de algunos documentos históricos, que numerosos grupos Diaguitas opusieron una tenaz y denodada resistencia a los intentos de conquista incaica y que incluso se rebelaron durante su dominio. ${ }^{23}$ Posiblemente otros grupos Diaguitas de esos valles pudieron haber aceptado ese dominio de forma más pacífica. De acuerdo con la hipótesis de Lorandi, en la región que se ubica el Pucará de Aconquija, los incas habrían tenido que lidiar con dos clases de fronteras en permanente conflicto: una de tipo «externa», hacia el oriente y contra las excursiones de los Lules; y una frontera «interna», originada a partir de la resistencia de algunas poblaciones Diaguitas. El control imperial en esa región se habría establecido a través de asentamientos delegados a poblaciones leales (mitmaqkuna) con el fin de controlar a las poblaciones locales y a los Lules. En este contexto, se sostuvo que la "frontera externa» estuvo controlada por el Pucará de Aconquija, un asentamiento ocupado por poblaciones trasladadas, como lo indican los escasos fragmentos cerámicos en superficie de estilos alóctonos (e.g. tipos Famabalasto negro sobre Rojo y Yocavil, originarios del área Chaco-santiagueńa) e Inca Provincial. ${ }^{24}$

${ }^{21}$ Núńez Regueiro 1974.

22 Tarragó 2000.

${ }^{23}$ Lorandi 1988.

${ }^{24}$ Kriscautzky 2002-2004: 178. 
- Ocupación estacional: Algunos especialistas señalaron que las mayores fortalezas de los Incas en sus fronteras fueron un fenómeno tardío en sus conquistas. ${ }^{25}$ En otros casos, que las grandes fortalezas no albergaron grandes contingentes militares y poblacionales, por lo que estos debían asentarse en zonas adyacentes a las fortalezas. ${ }^{26} \mathrm{Gu}$ nardo Lange, uno de los primeros exploradores que visitó el Pucará de Aconquija, sostuvo que el número total de estructuras del sitio no pudo haber sido suficiente para albergar a todo un ejército, por lo que sus habitantes habrían vivido en lugares cercanos. ${ }^{27}$

- Rango temporal: Según otras hipótesis, este sitio comenzó a edificarse a comienzos del siglo XVI o incluso después, en momentos cercanos a la llegada de los españoles a Cusco. Por esa razón, sus ocupantes no contaron con el tiempo suficiente para consumar su construcción y tuvieron que abandonar el sitio ante la súbita caída del imperio. ${ }^{28}$

Para formular esas hipótesis, no se contó con un cuerpo de datos lo suficientemente bien respaldados por resultados obtenidos en excavaciones y fechados radiocarbónicos. Por lo tanto, es todavía muy poco lo que en realidad se conoce sobre el Pucará de Aconquija en la actualidad. Estas insuficiencias se hicieron aún más evidentes al haberse minimizado o descartado los aportes que podrían obtenerse a partir del estudio de fuentes históricas. Así lo señaló el reconocido arqueólogo Alberto González anteriormente:

Otro sitio de excepcional importancia dentro de los límites tentativos de la "provincia» de Quire-Quire es el Pucará de Andalgalá, llamado también de Aconquija o Campo del Pucará. Este sitio quedó, por desgracia, marginado de las rutas de los primeros conquistadores españoles, por lo que carecemos casi de informaciones que proporcionen detalles acerca de su historia. ${ }^{29}$

\footnotetext{
${ }^{25}$ D'Altroy 2003: 252.

${ }^{26}$ Hyslop 1990: 163, 189.

${ }^{27}$ Lange 1892: 7; una perspectiva similar se observa en Hyslop 1990: 189.

${ }^{28}$ González 2000: 160; y Raffino 2007: 314.

29 González 1982: 334. Hyslop hizo eco de esta aseveración al asegurar posteriormente: «There are apparently no published early historical descriptions of the pucará and no hint of its original name» (1990: 182).
} 
Tal como se demostrará en el desarrollo de este trabajo, esa aseveración debe ser reconsiderada, ya que en realidad las informaciones históricas disponibles sobre el Pucará y sus posibles habitantes son más numerosas que lo pensado inicialmente.

Ahora bien, después de haber informado brevemente sobre las investigaciones e hipótesis formuladas en el pasado por otros investigadores, presentaré a continuación los resultados obtenidos en nuestro actual proyecto de investigación. Para ello, en una primera parte, se expondrán los resultados derivados de trabajos arqueológicos y, en una segunda, se desarrollará el análisis etnohistórico.

\section{EL PUCARÁ de ACONQUIJA A PARTIR DE LA ARQUEOLOGía}

Los trabajos arqueológicos que se vienen efectuando en el Pucará de Aconquija se empezaron a mediados del año 2009 y comprenden tanto excavaciones en el terreno como análisis en el laboratorio. Las primeras tareas realizadas fueron recolecciones superficiales por todo el sitio, mediadas por un previa sectorización areal arbitraria. Los restos materiales hallados fueron escasos. Todos ellos, además, corresponden a fragmentos cerámicos $(n=160)$ registrados generalmente en posición secundaria debido a procesos posdepositacionales, lo que produjo que muchos de ellos se encontraran en regular estado de conservación. En esa muestra se reconocieron fragmentos diagnósticos: bordes, asas y bases; formas reconocidas: aribaloides $(n=4)$, platos $(n=3)$, pie de compotera $(n=2)$, vasijas $(n=1)$ y ollas; y estilos elaborados durante momentos de dominación incaica en el NOA: Inca Provincial y Fase Inca.

En temporadas ulteriores, se excavaron los recintos previamente seleccionados. El objetivo propuesto fue obtener fuentes de información de orden cronológico-cultural, por lo que, mediante una cuidadosa estratigrafía, se trataron de establecer las posibles secuencias de ocupación y las actividades realizadas en el asentamiento. Las excavaciones se realizaron en ambos sectores del sitio, de forma íntegra $(\mathrm{n}=9)$ y parcial (sondeos; $\mathrm{n}=$ 8). A la fecha, se han excavado 17 recintos: 14 se encuentran ubicados en el sector sur y 3, en el sector norte. La mayoría de ellos constituían unidades habitacionales, pero también se excavaron recintos de plantas 
circulares y rectangulares destinadas probablemente al almacenamiento (qollqas), y un parapeto defensivo ubicado en los bordes del sitio. ${ }^{30}$ En cada uno de esos recintos se determinó una sola superficie de ocupación que, a juzgar por los restos materiales recuperados en la estratigrafía y por los fechados obtenidos, corresponden exclusivamente a momentos de dominio inca.

En las unidades habitacionales, se registraron evidencias materiales que generalmente indican la realización de múltiples actividades de orden doméstico: preparación, servido y consumo de alimentos y bebidas, y producción. Entre los materiales asociados a esas actividades se encontraron formas cerámicas utilizadas en la preparación y consumo de alimentos, almacenamientos de líquidos, restos de animales consumidos y descartados in situ (camélidos), materiales utilizados para la confección de textiles y elementos líticos destinados al procesamiento de vegetales comestibles.

La muestra cerámica obtenida en las excavaciones está compuesta por un total de 1124 fragmentos. Si bien el análisis correspondiente se encuentra todavía en una etapa preliminar, podemos adelantar una breve caracterización. La muestra está representada por tiestos clasificados como toscos $(n=470 ; 42 \%)$ y decorados $(n=654 ; 58 \%)$; la cerámica tosca comprende tanto a fragmentos peinados-rugosos como alisados. Las formas y morfologías son diversas, aunque una gran mayoría apunta a ollas (figura 4.A). Muchos de esos fragmentos presentan evidencias de haber sido expuestos al fuego directo (hollín). Aquellos decorados, además, se inscriben íntegramente dentro de estilos incaicos: Inca Provincial, la mayoría, y Fase Inca, los menos. Entre los últimos destaca un estilo del área Chaco-santiagueña: Famabalasto negro sobre rojo. Resultó llamativa

${ }^{30}$ En las excavaciones efectuadas en las qollqas solo se registraron escasos fragmentos cerámicos de tipo tosco. Se recolectaron muestras de sedimentos de manera sistemática que están siendo analizadas por técnica de flotación para estudios arqueobotánicos. En la excavación del parapeto no se registraron elementos líticos que pudieran haber sido destinados a un sistema de armas (piedras para hondas). Se recuperó una escasa cantidad de fragmentos cerámicos (toscos y decorados) entre los que sobresalió un fragmento de gran tamańo de plato inca (parte: cuerpo y borde; diseños lineares en negro sobre crema). 
la muy baja proporción $(\mathrm{n}=1)$ del otro estilo de esa área: Yocavil; aunque otros investigadores lo hallaron en la superficie del sitio. ${ }^{31}$ Otros estilos de la Fase Inca reconocidos en las excavaciones, aunque en proporciones muy inferiores, correspondieron a estilos del área Diaguita: Santamariano, Belén y Sanagasta. ${ }^{32}$ No se registraron estilos remitentes a ocupaciones previas (periodo Formativo-Medio) o posteriores (Hispano-Indígena). ${ }^{33}$

$\mathrm{El}$ análisis de formas presentes revela la presencia de un reducido conjunto de tipos morfológicos. De acuerdo con los parámetros de clasificación establecidos por Meyers sobre la base de 7 clases formales subdivididas en 14 tipos morfológicos, ${ }^{34}$ las formas registradas en las excavaciones corresponden a las encontradas usualmente en la vajilla imperial en las provincias. ${ }^{35}$ Las más frecuentes fueron los aríbalos o aribaloides y los platos, mientras que es llamativa la ausencia de ollas pedestal o "pie en compotera", aunque sí se llegaron a registrar dos casos en recolecciones superficiales. En las excavaciones efectuadas en ambos sectores del asentamiento, se registraron 12 aribaloides (figura 4.B), formas asociadas al almacenamiento y trasferencia de líquidos (chicha). Estas formas presentan una decoración en negro sobre engobe

${ }^{31}$ Una breve referencia de Lafone Quevedo hace suponer el hallazgo del tipo cerámico Yocavil en algún lugar del Pucará: «no quiero reproducir aquí la preciosa olla del Pucará en tres colores, negro, ante y encarnado en la que estos peines son de 12 y más dientes» (1892: 49). Posteriormente, Kriscautzky también mencionó el registro de escasos fragmentos Yocavil en superficie del Pucará (2002-2004: 178).

${ }^{32}$ Calderari y Williams proponen la siguiente clasificación: «Inca Provincial: piezas que imitan en mayor o menor grado a las cuzqueñas en su iconografía, morfología y estructura del diseño aunque difieren notablemente en su producción [...]. Inca Mixto: piezas que presentan una combinación de elementos cuzqueńos con otros no cuzqueños [...]. Fase Inca: tradiciones estilísticas locales o no locales preincaicas que durante su desarrollo histórico reciben el impacto cultural inca que se traduce en sutiles cambios [...] como es el caso de las urnas Santamarianas fase IV, pucos Santamaría negro sobre blanco, los estilos Yocavil Policromo y Famabalasto negro sobre rojo y el estilo Yavi Puneño» (Calderari y Williams 1991).

${ }^{33}$ Previamente, González y Núnez Regueiro mencionaron el registro de un fragmento de loza europea en superficie (1958-1959: 119).

${ }^{34}$ Meyers 1975.

${ }^{35}$ Un completo trabajo relacionado al análisis de la vajilla imperial inca en las provincias puede consultarse en Bray 2003. 
rojo, usualmente con iconografía de motivos geométricos y figurativos: cabezas de serpiente formadas por dos triángulos que podrían asociarse al área Diaguita. Además, se recuperaron 10 platos (figura 4.C), formas relacionadas al servido y consumo de alimentos sólidos. Una gran mayoría de ellos corresponden a los que presentan asa ornitomorfa (figura 4.C.1) y, en menor medida, con asa en ojal. En este caso, los fragmentos presentan una decoración en rojo, negro sobre rojo, negro sobre castańo y negro sobre crema.

Desde un marco general, tanto los aríbalos como los platos constituyen dos de las principales formas cerámicas reproducidas en los asentamientos de las provincias del Tawantinsuyu. ${ }^{36} \mathrm{Su}$ presencia en el Pucará pudo deberse al cumplimiento de las obligaciones de la reciprocidad de los Incas, particularmente a la prestación de alimentos y bebidas en agasajos y fiestas con los trabajadores del Estado. ${ }^{37}$ En las excavaciones también se registraron 3 torteros (muyunas), piezas de cerámica empleadas para la confección de textiles (figura 4.D).

Por otra parte, los materiales recuperados en las excavaciones destinados probablemente a la caza o al conflicto armado fueron escasos. Corresponden a esferas líticas ( $\mathrm{n}=3$; materia prima: oolita y arenisca; diámetros: entre 37 y $50 \mathrm{~mm}$; figura 4.E.1) y posiblemente fueron confeccionados para ser utilizados con hondas. También se recuperó una punta de proyectil (limbo triangular, pedunculada, materia prima: sílice). Además, en tareas de prospecciones realizadas por laderas y mesadas aledañas al Pucará, se registraron otros tres elementos líticos que pudieron haber pertenecido a sistemas de armas arrojadizas (formas: óvalos alargados; materia prima: leucogranito de grano fino y anfibolita; diámetros: entre 27 y 29 mm, longitud: entre 52 y $58 \mathrm{~mm}$; figura 4.E.2).

Los análisis arquitectónicos efectuados en las excavaciones revelaron que las bases de las paredes de los recintos excavados se encontraban generalmente en muy buen estado de conservación. Estas fueron instaladas sobre sedimentos de tipo ripioso acondicionados intencionalmente. En algunos casos, particularmente en las estructuras localizadas sobre terrenos con

${ }^{36}$ Bray 2004.

${ }^{37}$ Véanse, por ejemplo, Dietler y Hayden 2001; Jennings 2004; y Kaulicke 2005. 

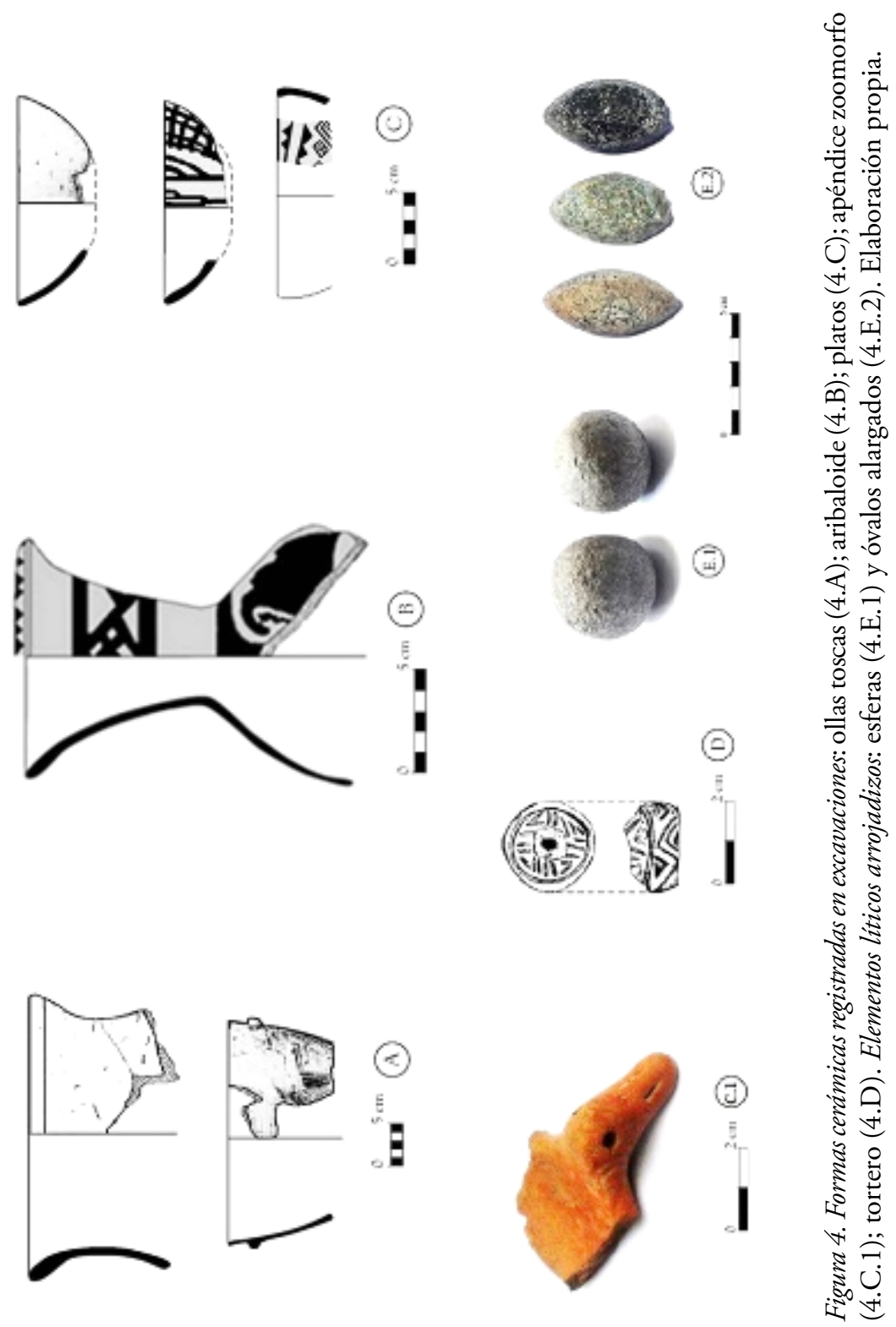
pendiente, el desnivel fue solucionado con relleno de sedimento para confeccionar la superficie ocupacional. Identificamos dos tipos generales en las técnicas constructivas y materias primas utilizadas. En el sector sur, el patrón recurrente fue la colocación de piedras planas de manera horizontal, una sobre otra sucesivamente. En cambio, en dos de los recintos excavados en el sector norte, se registraron técnicas alternativas: piedras lajas planas clavadas a intervalos regulares y, en el lado interno, de forma vertical directamente en el piso, a manera de refuerzo o guías en las bases de las paredes.

Por otra parte, en numerosas paredes de los recintos del Pucará es posible distinguir la colocación de piedras lajas intercaladas con otros tipos de rocas (cuarzo, feldespato), lo cual les otorgaba un marcado contraste cromático. Tanto la técnica de colocar piedras planas clavadas de forma vertical en la base de las paredes ${ }^{38}$ como la distribución de piedras intercaladas en las paredes de diferentes colores (cuarzo=blanco; feldespato=rosado; lajas=gris oscuro) se registraron en áreas aledañas al bolsón de Andalgalá y en asentamientos del valle de Santa María (al oeste del Pucará de Aconquija); además, se determinó que pertenecieron al periodo tardío local y que su uso era simbólico-ritual. ${ }^{39}$ Se debe mencionar que en ninguna de las excavaciones llevadas a cabo en el Pucará se registraron evidencias de abandono violento o súbito que puedan relacionarse con situaciones conflictivas o de abierta hostilidad (como techos quemados o restos óseos humanos con evidencias directas de esas situaciones).

Uno de los objetivos principales de nuestra investigación fue generar un marco cronológico de ocupación del sitio. Con este fin se procesaron dos muestras obtenidas en recintos de ambos sectores en los Laboratorios LATyR (Universidad Nacional de La Plata) y en el Center for Applied Isotope Studies (University of Georgia). La calibración se realizó utilizando la curva del hemisferio sur $\mathrm{ShCal} 13^{40}$ por medio del software OxCal v. 4.1 .5 (tabla 1 y figura 5 ). ${ }^{41}$

\footnotetext{
38 Nastri 2001.

39 Reynoso 2009; Tarragó y González 2004.

40 Hogg y otros 2013.

41 Ramsey 2009.
} 


\begin{tabular}{|c|c|c|c|c|}
\hline $\begin{array}{l}\text { Cód. } \\
\text { lab. }\end{array}$ & Material & $\begin{array}{l}\text { Edad } \\
{ }^{14} \text { CAP }\end{array}$ & $\begin{array}{l}\text { Calibración DC } \\
1 \text { sigma }(68,2 \%)\end{array}$ & $\begin{array}{l}\text { Calibración DC } \\
2 \text { sigma }(95,4 \%)\end{array}$ \\
\hline $\begin{array}{l}\text { UGAMS } \\
-8560\end{array}$ & $\begin{array}{l}\text { Óseo camélido } \\
(\delta 13 \mathrm{C}-15,8 \% \text { })\end{array}$ & $460 \pm 25$ & $1443-1478(68,2 \%)$ & $\begin{array}{l}1434-1499(91,9 \%) \\
1598-1610(3,5 \%)\end{array}$ \\
\hline \multirow[t]{4}{*}{ LP-2499 } & $\begin{array}{l}\text { Carbón vegetal } \\
\text { (estimado } \\
-24 \pm 2 \% \text { ) }\end{array}$ & $480 \pm 60$ & $\begin{array}{l}1414-1498(65,4 \%) \\
1601-1607(2,8 \%)\end{array}$ & $\begin{array}{l}1397-1518(74,6 \%) \\
1539-1626(20,8 \%)\end{array}$ \\
\hline & \multicolumn{4}{|c|}{ Test T (Ward y Wilson 1978) } \\
\hline & Test $T$ & G. de Lib. & c2 $(=, 5)$ & Resultado \\
\hline & 0,1 & 1 & 3,8 & Indistinguibles \\
\hline
\end{tabular}

Tabla 1. Fechados radiocarbónicos del Pucará de Aconquija. Elaboración propia.

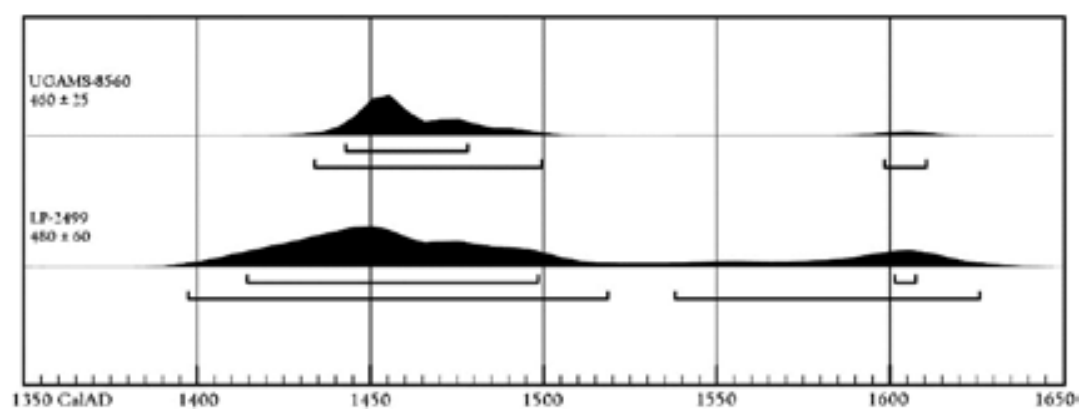

Figura 5. Fechados calibrados del Pucará de Aconquija. Elaboración propia.

Ambos fechados presentan marcada similitud y, por los márgenes de error de las técnicas aplicadas, no puede afirmarse con certeza cuál de los dos eventos es más antiguo. Los valores fueron estadísticamente indiferenciables al someterlas al Test $T$ de Ward y Wilson. ${ }^{42}$ Esto nos indica que los dos fechados son de momentos muy próximos en el tiempo. Dentro de la calibración con dos sigmas, los rangos más probables para cada fechado

${ }^{42}$ Ward y Wilson 1978. 
son $1434-1499(91,9 \%)$ y 1397-1518 (74,6\%) respectivamente. Las implicancias generales de estos resultados serán discutidas más adelante.

Debo señalar que actualmente nos encontramos investigando un recinto en particular del Pucará de Aconquija, ubicado en el sector sur y en la porción más elevada y llana de una pequeña loma. El recinto se distingue nítidamente del resto del conjunto edilicio del sitio por presentar una amplia roca de afloramiento delimitada intencionalmente en el espacio interior circunscripto por las paredes. ${ }^{43}$ Los investigadores que analizaron esas grandes rocas de afloramientos demarcadas intencionalmente con arquitectura en otros sitios del Tawantinsuyu - como también en periodos previos - sostienen que se trata de espacios sagrados-ceremoniales: wak'as. ${ }^{44} \mathrm{El}$ registro de la wak'a en el interior del Pucará, junto con la wank'a ubicada a un costado del qhapac ñan, agrega nuevos y sugerentes componentes a la investigación de aspectos funcionales del Pucará que van más allá de los estrictamente defensivo-militares.

Una de las últimas tareas realizadas en el terreno fueron prospecciones pedestres por áreas circundantes al Pucará que no contaban con reconocimientos previos. Se registraron 30 sitios que en alta proporción (29/30) corresponden a asentamientos con arquitectura visible en superficie y, en algunos casos, con fragmentos cerámicos asociados. Todos los sitios ocupan áreas reducidas y están constituidos por un bajo número de recintos habitacionales. De acuerdo con los registros preliminares, un conjunto menor correspondería tentativamente al periodo formativomedio $(n=8)$; los restantes podrían pertenecer al momento de dominio inca $(n=22)$. Ninguno de esos sitios presenta rasgos arquitectónicos de corte defensivo-militar, algo que sería esperable si fueran correctas las previas suposiciones de haber sido esa un área constantemente acechada por las poblaciones del este. En cambio, por su organización estructural pensamos que podrían haber cumplido funciones ligadas al encierro de animales (corrales) y otras relacionadas al cultivo de vegetales.

43 Esta particularidad fue registrada anteriormente en una breve visita que realizó Hyslop al Pucará de Aconquija (1990: 185).

${ }^{44}$ Bray 2015; Dean 2010; y Niles 1987. 
Los registros de fragmentos cerámicos en superficie asociados a los sitios incas dieron cuenta de tipos toscos y decorados; dentro de estos últimos se reconoció mayoritariamente el estilo Inca Provincial y, en menor medida, estilos originarios del área Chaco-santiagueña (Famabalasto negro sobre rojo y escasos registros del tipo Yocavil). Las formas cerámicas reconocidas remiten a vasijas asociadas a la preparación y consumo de alimentos (ollas, platos) y al almacenamiento de líquidos (aribaloides).

En resumen, esta síntesis de las actividades y los análisis efectuados desde nuestro proyecto y los resultados logrados en él nos permiten reconstruir con cierto grado de detalle diversos aspectos ligados a la funcionalidad y ocupación del sitio. Estos resultados serán evaluados con mayor profundidad después. A continuación, se analizan referencias extraídas de fuentes históricas comprendidas entre los siglos XVI y XVIII que se relacionan con el Pucará de Aconquija y sus posibles habitantes, los Malle/Malli.

\section{EL PUCARÁ DE ACONQUIJA SEGÚN LAS FUENTES HISTÓRICAS}

En el estudio de las fuentes históricas disponibles para el NOA no es frecuente hallar menciones específicas sobre asentamientos indígenas de tipo defensivo (pucará). El caso del Pucará de Aconquija podría ser una excepción a esa regla. En este sentido, se pudo corroborar que las referencias históricas sobre ese Pucará son más numerosas de lo que algunos investigadores han admitido. De todas maneras, las menciones que pudimos recobrar se pueden organizar en dos grupos. Uno de ellos, por un lado, se relaciona con alusiones "probables», ya que no poseen la precisión y especificidad requeridas. Estas menciones se encuentran conexas a ciertos pasajes incluidos en el contexto general de construcción de fortalezas por mandato de los Incas en la región de Tucumán y provienen básicamente de crónicas clásicas y de un documento específico y temprano. Otro grupo de referencias, por otro lado, presenta información de un carácter más preciso sobre el Pucará y sobre sus posibles habitantes; estas se ubican en documentos más tardíos (principios del siglo XVI hasta el siglo XVIII) y de carácter local. 


\section{El Pucará de Aconquija en la incertidumbre de ser quien podría ser}

Desde un marco general, la forma y fecha en que diversas regiones del NOA fueron integrados al Tawantinsuyu aún es fuente de discusión, especialmente en las áreas que fueron ocupadas por poblaciones Diaguitas y el Tucumán prehispánico. Algunos pasajes de las crónicas pueden ofrecer algunas pistas, aunque la validez de esas referencias no es de modo alguno concluyente. Así, se puede reconocer en una cita de la obra de Pedro Cieza de León la posibilidad que los nativos del Tucumán prehispánico estuvieran efectivamente sujetos a los Incas en alianza (asimétrica, claro está) y que parte de esa región haya sido fronteriza:

en tiempo del Inga Yupangue, padre que fue del rey Topa Inga, e abuelo de Guayna Capac, fueron enviados por su mandado ciertos orejones [...] e concertaron que su amistad fuese perpetua, y ellos obligados a no más de a guardar aquella frontera, que no entrase nenguna gente por allí a dar guerra a su Señor, como esta paz fue hecha. ${ }^{45}$

La construcción de fortificaciones defensivas por mandato de los Incas en nuestra región de estudio y la relocalización de poblaciones destinadas a cumplimentar funciones en esas fortalezas se puede reconocer en otro documento temprano. En una Probanza elaborada en la ciudad de Cusco en el año 1569, se rememora a miembros sobrevivientes de ayllus reales y se solicita a las autoridades españolas acreditar su ascendencia de Incas conquistadores. De una sección en particular de ese documento, la «Memoria de las Provincias», se puede rescatar un dato específico sobre el paso del conquistador Thupa Inca por el Collasuyu:

y entró en la prouinçia de los chichas y moyomoyos y amparais y aquitas copaypo churomatas y coracos y llegó hasta los chiriguanas hasta tucumán $\mathrm{y}$ allí hiço una fortaleça y pusso muchos indios mitimaes. ${ }^{46}$

A partir de esta argumentación sobre la articulación entre fortalezas y mitmaqkuna en la región durante la conquista incaica, se pudo reconocer

${ }^{45}$ Cieza de León 2005: 319; el énfasis en esta y las siguientes citas ha sido agregado por el autor. Esta aseveración fue discutida por Lorandi (1980: 158-160).

${ }^{46}$ Rowe 1985: 215, 226. 
otra probable invocación del Pucará de Aconquija en los recuentos del padre José de Acosta sobre la extensión y duración del imperio de los Incas:

Pasando Quito hasta el río de Pasto hacia el norte, y llegaron a Chile hacia el sur, que serán cuasi mil leguas en largo; por lo ancho hasta la mar del sur al poniente, y hasta los grandes campos de la otra parte de la cordillera de los Andes, donde se ve hoy día, y se nombra el Pucará del Inca, que es una fuerza que edificó para defensa hacia el oriente. No pasaron de allí los Incas por la inmensidad de aguas, de pantanos, lagunas y ríos que de allí corren. ${ }^{47}$

Lamentablemente no existen bases firmes que nos permitan asegurar que ese «Pucará del Inca» sea efectivamente el Pucará de Aconquija. Probablemente sea el mismo que, como veremos más adelante, se menciona en la merced del capitán Sebastián de Loria. Por otro lado, la «defensa hacia el oriente» en la cita de Acosta puede aludir a los belicosos y hostiles grupos nómades Lules.

Otra posible referencia del Pucará de Aconquija se encuentra en la obra del padre dominico Reginaldo Lizárraga:

Al licenciado Lerma le subcedió Juan Ramírez de Velasco, caballero bien intencionado, el cual pobló dos pueblos de españoles en las faldas de la cordillera vertientes a Tucumán, el uno donde fue poblado los años pasados la cibdad de Londres [...] el otro más adelante, a la misma falda de la cordillera; es tierra fértil y que produce abundancia de oro y plata [...] el Inga los tuvo subjetos, y por la falda desta cordillera llevaba su camino real hasta Chile; servíanle y tributábanle oro en cantidad, y de allí se lo traía acá al Perú; su capitán, con la gente de guerra, estaba en un fuerte recogida, y no salía del sino era cuando algunos indios se le rebelaran; reducidos y castigados, volvíase a su fuerte. ${ }^{48}$

Estos últimos fragmentos presentan algunas dificultades. La mención de las «faldas de la cordillera vertientes a Tucumán» remite seguramente a la sierra de Aconquija, área rica en recursos minerales. La noticia de «Londres» nos sitúa geográficamente, pero la mención de «el otro más adelante» sin más precisiones no permite puntualizar más. Sin embargo,

\footnotetext{
47 Acosta 1894, II: 119.

${ }^{48}$ Lizárraga 1916, II: 241-242.
} 
es importante resaltar nuevamente la afirmación de que los Incas estaban establecidos «en las faldas de la cordillera vertientes a Tucumán»y que allí se encontraba "gente de guerra [...] fuerte recogida» (relación fortaleza-mitimaqkuna).

De todos modos, estas apelaciones a los párrafos de Acosta, Lizárraga y la «Memoria de las Provincias», por la falta de especificidad ya advertida, revisten solo un carácter informativo y de contextualización general.

\section{El Pucará de Aconquija y sus habitantes «con nombre y apellido»}

Las indagaciones en textos históricos ceñidos particularmente a menciones concretas y específicas sobre el Pucará de Aconquija y sus posibles habitantes tuvieron mejor fortuna en documentos más tardíos y de carácter local. Como señalé al comienzo de este trabajo, revistió particular importancia el poder contar con la confirmación de merced de tierras otorgada al capitán Sebastián de Loria. ${ }^{49}$ Tal como se certifica en esos documentos, el 25 de noviembre de 1626, este capitán solicitó al alcalde de la ciudad de San Juan Bautista de la Paz que se le ratifique la merced otorgada por el gobernador Luis de Quiñones Osorio una década atrás. En aquella primera merced, del 8 de abril de 1616, se pidió la posesión de unas tierras despobladas:

por parte de el Capitán Sebastián de Loria se me ha hecho Relación que en el valle de Anconquija lo que llaman Pucara, está un pedazo de tierras Baca desocupadas, y se me ha pedido y suplicado por su parte le haga merced de ella. ${ }^{50}$

En ese documento este capitán describe su propiedad de la siguiente manera:

${ }^{49}$ El capitán Sebastián de Loria y Carrasco fue vecino fundador de la ciudad de La Rioja. Estuvo casado con doña Catalina de Artaza, hija del capitán don Juanes de Artaza, uno de los primeros conquistadores del Tucumán y también vecino fundador de La Rioja. ${ }^{50}$ Confirmación de la entrega de una merced al capitán Sebastián de Loria, 1626, Archivo Histórico de Catamarca, Causa Civil, Sección Judicial, Caja n. ${ }^{\circ}$ 1, Expediente n. ${ }^{\circ} 22.746$. 
Tengo y poseo la estancia y tierras de Pucara de Anconquija, y Pampa de la Sierra, con los Rios, arroyos, aguadas y valles de ella hasta la sierra honda y hacia parte de Singuil hasta el arroyo donde antiguamente estuvieron pobladas de indios del pueblo de Maliengue. ${ }^{51}$

Una vez establecida la localización de esas tierras (valle de Aconquija) y la mención específica de su nombre (Pucará), se destaca a continuación un párrafo aclaratorio:

que linda con la estancia y tierras que hice merced antes de ahora al dicho Capitán Sebastián de Loria, que corre desde el Pucará que llaman del Inga el valle abajo, cumplida la merced..$^{52}$

Indiscutiblemente debo poner énfasis en una expresión en particular: la preexistencia de un «Pucará que llaman del Inga». Como punto de referencia de importancia, presenta connotaciones funcionales - Pucará-y de filiación étnica —-Inga - en el valle de Aconquija. Sin embargo, antes de dar por sentado que este «Pucará del Inga» está asociado con el Pucará de Aconquija, determiné profundizar las indagaciones. En primera instancia, se debían establecer adecuadamente los límites de la merced a partir de actuales demarcaciones territoriales. Los análisis realizados anteriormente por el historiador Félix Brizuela del Moral resultaron de vital importancia, pues, de acuerdo con sus pesquisas, se estableció que toda esta merced correspondía a lo que actualmente se conoce como "Campo del Pucará». Específicamente, dicha merced abarcaba el territorio comprendido entre la cumbre de la Chilca y el paraje de Aguas de las Palomas, hasta la localidad de El Alamito y los Altos de la Junta por el norte, y la parte de Singuil por el oeste. ${ }^{53}$

En otro apartado de la merced del capitán de Loria se señaló la presencia en esas tierras de un grupo étnico:

os hago merced hasta la junta de los Ríos que esta dos leguas de Anconquija, camino de Malle que va al dicho Pueblo de Anconquija, que sus aguadas se llaman Tacalam y el otro se llama Oscaam que están entre las juntas de

${ }^{51} \mathrm{Ib}$

${ }^{52} \mathrm{Ib}$.

${ }^{53}$ Brizuela del Moral 2003: 127-129. 
los Ríos, y la Estancia que tenia poblada y más media legua pasado la junta de los Ríos debajo de Anconquija con todo el anchor que tiene el dicho Valle hasta el alto dela Sierra Nevada [Sierra de Aconquija] con todas las aguadas, arroyos, Manantiales y Cañadas que tuviese y asia la parte de Single [Singuil] hasta topar con el arroyo donde antiguamente fueron y estubieron Poblados los Malles cuando se Retiraron de su asiento y pueblo de Malle. ${ }^{54}$

El pueblo «Malle» (también «Maliengue»), según se desprende de la merced, debió estar establecido en el valle de Aconquija y relacionado especialmente con el «Pucará del Inga». ${ }^{55}$ Desafortunadamente, nuestras búsquedas sobre otras referencias que ubiquen a los Malle en el valle de Aconquija para las primeras décadas de la colonia española en diferentes archivos históricos provinciales no tuvieron los resultados deseados. Sin embargo, se logró reconstruir con cierto grado de detalle el derrotero histórico de este grupo étnico a partir de documentos provenientes de los archivos históricos de Tucumán, Catamarca y Córdoba que fueron reproducidos anteriormente en otras publicaciones.

La más temprana alusión reconocida sobre los Malle es del 4 de noviembre de 1607 . Atañe a una breve cita extraída de una carta elevada por el capitán Gaspar Doncel al gobernador del Tucumán Alonso de Rivera, por la fundación de San Juan Bautista de la Ribera. Allí se describe específicamente: «Malle: pueblo del capitán Juan de Espinoza que está diez leguas de esta ciudad tiene indios de vista treinta y cinco indios». ${ }^{56}$ Un año después de esa carta, el mencionado capitán Espinoza

${ }^{54}$ En opinión de Lafone Quevedo, la primera expatriación de los Malli de su lugar de origen debería corresponder a la época de Alonso de Ribera (1607); por otra parte, la localidad de Singuil, departamento Ambato, provincia de Catamarca, se encuentra ubicada a corta distancia del Pucará, hacia el sureste (Lafone Quevedo 1898: 211-212). 55 Debe destacarse que la mención en ese documento sobre los Malli en estrecha relación con el Pucará de Aconquija no pasó desapercibida: en dos de sus más celebradas obras de finales del siglo XIX, Lafone Quevedo dejó expresa constancia de su convencimiento de que ese grupo étnico efectivamente ocupó (y defendió) esa fortaleza incaica. Sin embargo, también debe señalarse que esas aseveraciones se sustentaban solamente en lo expresado en la merced de Sebastián de Loria. Véanse Lafone Quevedo 1888: 4, 23, 144-145; y 1898 : 212, 262.

${ }^{56}$ Copia de la carta del capitán Gaspar Doncel, Teniente de La Rioja y San Juan Bautista de la Rivera, 4 de noviembre de 1607, para el gobernador Alonso de Rivera (Larrouy 2004: 204). 
se encontraba disputando legalmente la posesión de dos pueblos con otro vecino de la ciudad de San Miguel de Tucumán, el capitán Simón de Villadiego. ${ }^{57}$ En ese documento se describieron los alegatos de cada una de las partes en el litigio. Por un lado, Villadiego fundamentaba tener derechos sobre los pueblos "Malincho» $\mathrm{y}$ "Tactaxita» de indios Lules, en los cuales Espinoza se había "metido" y de los cuales obtenía beneficios sin previa concertación. Este último, por otro lado, alegaba tener derechos de encomienda sobre los pueblos "Mallempes o Mallenga» $\mathrm{y}$ «Tactao», de indios Diaguitas. Lamentablemente en ese documento no quedó constancia de la localización precisa de esos pueblos; sin embargo, suponemos con cierto grado de confianza que Mallempes se referiría al pueblo Malle encomendado en 1607 precisamente a Espinoza.

Parte de esta controversia puede explicarse, según el padre Pablo Cabrera, ${ }^{58}$ por los cambios de terminología de esos pueblos de acuerdo con el grupo étnico que lo ocupaba. Según Cabrera, las denominaciones de los pueblos Mallempes y Tactao tienen su origen en la lengua kakana hablada por Diaguitas. Su contraparte en Lule sería Malincho y Tactaxita. Estos cambios en los términos aplicados también pueden ser apreciados en la terminología del otro pueblo Payao (Diaguita) Payaosita (Lule). Para Espinoza estas trasmutaciones en los nombres se debían a que, "por ser propio de los indios Lules de esta provincia como gente que anda vagando por diferentes partes y no tener asiento en una parte segura, mudando los nombres conforme en el sitio donde paran $"{ }^{59}$ Precisamente, para el caso que nos interesa, el padre Cabrera reflexionó que Malincho "vertido al diaguita es Mallenja (Mallinga)». ${ }^{60}$ De todas maneras, la disputa legal se resolvió cuando Espinoza se comprometió a pagar a Villadiego con dinero y ganado vacuno a cambio de la renuncia a los derechos sobre esos pueblos. Nos quedaría, entonces, que el pueblo de variada etnonimia «Malincho - Mallempe - Mallinga - Mallenja», según Cabrera, era originalmente Diaguita. El cambio del nombre a «Malincho»

\footnotetext{
${ }^{57}$ Lizondo Borda 1936-1949, II: 37-42.

${ }^{58}$ Cabrera 1910; y 1926: 42, 150-151.

${ }^{59}$ Lizondo Borda 1936-1949, II: 146.

${ }^{60}$ Cabrera 1910: 42.
} 
pudo deberse a una posterior ocupación por parte de poblaciones Lules. Ahora bien, de ser esto así y de efectivamente tratarse del pueblo Malle/ Malli que se encontraba en el Campo del Pucará-Pucará de Aconquija, no queda realmente claro si eran los Lules nómades o sedentarios ni la fecha de esa reocupación-cambio de nombre. En todo caso, estos sucesos debieron acontecer en momentos de la colonia espańola y no durante el dominio inca.

Muy pocos años después de esa disputa volvimos a reconocer a los Malle en otros textos históricos que los ubicaban entre poblaciones Diaguitas que habitaban las zonas serranas de Aconquija. En los recuentos realizados por los jesuitas Pedro Lozano y Nicolás del Techo, se tienen precisas noticias de una misión evangelizadora realizada por los también padres jesuitas Diego de Boroa y Juan Darío. ${ }^{61}$ Esos sacerdotes tuvieron el cometido de catequizar y pacificar ciertas regiones del oeste de la provincia de Catamarca a finales del año 1611, con el fin de satisfacer un pedido del entonces nuevo gobernador del Tucumán, Luis Quiñones Osorio. Debe señalarse en primera instancia que, al referirse a los lugares recorridos por Darío y Boroa, se hizo explícito que los pobladores del "valle de Anconquixa» pertenecían concretamente a grupos Diaguitas, sin hacerse ninguna referencia a la existencia de pueblos Juries (Lules-Tonocotés):

que diesen principio a la pacificación y cultivo de los Diaguitas, por el Valle de Anconquixa, situado entre las Sierra de aquella Ciudad, y de la de Londres, y no lexos de la de Yocabil en Calchaquí. Emprendieron el famosísimo camino a 21 de Octubre y con imponderables trabajos llegaron a Anconquixa, donde recibidos con extraordinario regocijo. ${ }^{62}$

Lozano agregaría otras referencias sobre estos Diaguitas asentados en Aconquija. Es particularmente interesante la referencia a los Malle dentro de esta categoría étnica:

${ }^{61}$ Del Techo 1897; y Lozano 1754-1755, II.

${ }^{62}$ Lozano 1754-1755, II: 294. 
Informáronse después de un Español práctico del País, qual sería la gente Diaguita mas necesitada de aquellas Sierras, les asseguro, que ningunos mas, que los Pueblos de Guassan, y Malle, donde avían muerto algunos Españoles. ${ }^{63}$

La ubicación precisa de Malle, más allá de la referencia de «aquellas sierras y Diaguitas», no quedó plasmada de forma concreta en el texto de Lozano. Pero si seguimos el itinerario del viaje constatamos que los padres Darío y Boroa arribaron primero al valle de Aconquija, en donde se comentó lo referido a Malle y a una viuda de ese pueblo. Lozano dejó en claro que posteriormente los dos padres «Passaron a Andalgalá», donde se encontraban los "Huachasses», e hizo una última referencia étnica sobre los "Guassan», "gente Diaguita de aquellas sierras». ${ }^{64} \mathrm{El}$ padre Del Techo comentó también que Darío y Boroa «recorrieron las exiguas aldeas habitadas por los guasanos, maleos, huachases y andalgalas». ${ }^{65}$

En definitiva, la ubicación del pueblo Malle en el valle de Aconquija en el año 1611 es clarificadora, en tanto la posterior referencia histórica del capitán Sebastián de Loria (1616-1626) los ubica en Andalgalá previo paso y asentamiento en la localidad de Singuil. Las razones que determinaran el primer traslado de los Malle a Singuil, al sur del Campo del Pucará, no se conocen aún. Lo seguro es que la permanencia de los Malle en Singuil no fue por un tiempo prolongado, ya que la merced de Sebastián de Loria de 1616 los ubica en la localidad de Andalgalá, seguramente por decisión de doña Leonor Pérez, esposa de Espinoza, aludido como encomendero de los Malle en la carta de Gaspar Doncel de $1607 .{ }^{66}$
63 Ib.: 295.
${ }^{64}$ Ib.: 296.
${ }^{65}$ Del Techo 1897: 193-195.
66 "Malli» no es un etnónimo que pueda ser reconocido solamente en las fuentes histó- ricas. El traslado de esta población en el siglo XVII a la ciudad de Andalgalá dio origen a un distrito localizado al sur de esa ciudad que aún conserva el nombre de ese grupo étnico. Este traslado puede ser confirmado a partir de lo expresado en la confirmación de merced del capitán Sebastián de Loria: «y hacia la parte de Singuil hasta el Arroyo donde antiguamente estuvieron poblados los indios de el Pueblo de Mallengue Encomienda que 
Por lo visto hasta aquí, la estructuración étnica en el valle de Aconquija durante la primera década del siglo XVII encontraría a los Malle/Malli ubicados en el sur, posiblemente en el Campo del Pucará y en cercanía espacial con los Aconquijas, localizados hacia el norte. Mientras que los Huachasse y Andalgalas se encontrarían asentados en Andalgalá y en proximidad espacial con los Guassan. ${ }^{67}$

De otros enunciados dedicados por Lozano a la visita de los padres Darío y Boroa en Aconquija y Andalgalá se extrajeron otros valiosos comentarios para esta investigación. En primer lugar, notamos que los indios de estas dos áreas contaban con caciques —indios principales—:

pero embiaronles un mensaje con cierto Indio principal, cuya huella fueron siguiendo por caminos asperísimos [...] señalándose entre todos el Cacique mas principal del Pueblo, que iba por delante de todos sus vasallos en el exemplo de piedad, y devoción. ${ }^{68}$

También se afirmó que, cuando los padres arribaron a la zona, "Gustaron mucho los Diaguitas de su ida, y saliendo de sus guaridas, se fueron recogiendo a sus Pueblos, á quienes recibían muy alegres». Asimismo, de esos recuentos se rescata que los aborígenes locales contaban con adoratorios «que su Idioma llaman $Z u p c a$, que significa lugar de los sacrificios, y lo daban bien á entender las señales, que allí vieron». ${ }^{69}$ Un último comentario de interés, que aporta un dato concreto sobre evidencias materiales del dominio incaico en la zona fue el siguiente:

era tierno espectáculo ver la devoción, y compuncion [de los indios de Andalgalá] con que se llegaban al Tribunal de la Penitencia, armados de sus quipos, que son unos hilos con sus nudos, por donde declaraban el numero de sus pecados, con la facilidad, que si los llevaran escritos, y con la expedicion, que si lo huvieran acostumbrado muchos años. ${ }^{70}$

es de Leonor Peres que ahora están asentados en el valle de Andalgalá». Véase Guzmán 2010: 121; y Larrouy 1941: 47.

${ }^{67}$ Larrouy 1941: 48.

${ }^{68}$ Lozano 1754-1755, II: 295.

${ }^{69} \mathrm{Ib} .: 295$.

${ }^{70} \mathrm{Ib} .: 296$. 
En fechas levemente posteriores a las referencias de Lozano y Del Techo y de la confirmación de la merced de 1626 a Loria, los Malle reaparecen participando activamente en los aciagos sucesos históricos acontecidos a escala regional. Según se desprende de algunos documentos, los Malle formaron parte de los cruentos enfrentamientos de parcialidades indígenas contra tropas españolas en el "Gran Alzamiento Calchaquí» (1630-1643) dentro de una compleja red de parentesco y alianzas con otros grupos indígenas rebeldes. ${ }^{71}$

Particularmente, en uno los pasajes históricos relativos a esos acontecimientos se reconoció una nueva alusión al Pucará de Aconquija. En cartas escritas entre 1633 y 1639 por el gobernador del Tucumán Felipe de Albornoz al rey de España, adquiere notoriedad la presencia del almirante Salvador Correa de Sáa Benavides, el cacique Pedro Chumay y ciertos detalles de las alianzas y batallas entabladas entre los indios de Aconquija, Malles y Guasan contra los españoles. En primera instancia, el gobernador Albornoz mencionaba, en 1633,

como fueron al almirante Saluador Correa de Ssaa, cauallero del áuito de Santiago, hijo de Martín de Ssaa, Gouernador del Río Jeneiro, de quien demás de su buen nombre y auersse siempre criado en la guerra, se auía hecho espiriencia en esta prouincia en la correduría que por mi horden hiço en la ciudad de Tucumán contra los yndios del pucara de Aconquija y sus aliados a quienes venció en batalla con muerte de muchos dellos y prissión de su principal cazique, llamado don Pedra Chumay. ${ }^{72}$

En otra carta, fechada también en 1633, este mismo gobernador alude a la batalla ocurrida el 17 de enero de 1632 entre Aconquijas — junto con los convocados Mallis y Guasanes, comandados por don Pedro Chumay- y los españoles de Salvador Correa y sus «indios amigos». Esta batalla finalizaría con la dolorosa derrota para los nativos descrita brevemente en la anterior cita. En otro apartado de ese mismo docu-

${ }^{71}$ Sobre la participación de los Malli en el contexto general de esos acontecimientos y las redes de parentesco y alianzas indígenas, véase Schaposchnik 1997: 309-340.

${ }^{72}$ Citado en Pérez Sáez y Osán de Pérez Sáez 1997-1998, II: 114. Las abreviaturas han sido desarrolladas. 
mento se rememora una batalla entablada posteriormente dentro del convulsionado ambiente entre las tropas españolas comandadas por los capitanes Juan de Ceballos y Juan Gutiérrez de Leguizamón, y los Malle «y otros muchos de los pueblos alsados hecho una grande junta» en proximidades de la localidad de Singuil. El saldo de esta contienda no sería favorable para las poblaciones indígenas, "con muerte de más de sien yndios de pelea y mas de sesenta piesas cautibas», en lo que en definitiva sería para los espańoles, «una victoria de gran ynportancia por el yntento que trayan de apoderarse del valle de Catamarca y siena de Santiago sin otras corridurias de menor ynportancia en que se consiguieron buenos efectos». ${ }^{73}$ En un extracto de otra carta del gobernador Albornoz, del ańo 1639 pero referida a los acontecimientos de 1632, se menciona un final trágico para esta población: «murieron casi todos los del pueblo de Malle principales convocadores del valle de Andalgalá». ${ }^{74}$ El destino de los Malle, luego de esos problemáticos y desgraciados sucesos, corrió la misma suerte que numerosas poblaciones locales derrotadas por los españoles: fueron desnaturalizados a otras regiones, posiblemente a Huaco en la provincia de La Rioja. ${ }^{75}$ De acuerdo a Boixadós un grupo de poblaciones del oeste catamarqueño (valle de Hualfín y valle de Andalgalá) fueron trasladadas al valle de Famatina en el año 1635. En esa región se conformaría la reducción multiétnica de Malligasta, ${ }^{76}$ toponimia ciertamente sugestiva por su muy probable raíz en "Malli».

Evidentemente el traslado de los Malli/Malle a otras regiones hubo de motivar el deseo por apropiarse de las tierras ahora desocupadas. Hacia 1636 se produce la confirmación de entrega de encomiendas («indios, pueblos y repartimiento de Mallenge e Iumanjuna (Yumansuma)»

\footnotetext{
73 Citado en Boman 1918: 183.

${ }^{74}$ Citado en Schaposchnik 1997: 323.

75 Balesta, Zagorodny y Flores 2006: 107; y Lafone Quevedo 1898: 212.

${ }^{76}$ Boixadós 2007-2008: 11. Esta sugestiva relación fue notada también por Lafone Quevedo (1898: 212) y De la Vega Díaz (1994). Aunque, tal como expresara R. Boixadós, "La repetición de topónimo no siempre es resultado de traslados coloniales; a veces remiten a procesos prehispánicos más complejos como la ocupación simultánea de tierras por parte de un mismo grupo o la presencia de población foránea situada en distintos sitios según su función» (Boixadós 2008: 255).
} 
al capitán Juan Ceballos Morales. Estas encomiendas, de propiedad precedente del capitán Juan de Espinoza Negrete y posteriormente de su viuda, doña Isabel Pérez Bohórquez, habían quedado «vacos», según lo estableció el gobernador de la provincia de Tucumán, don Felipe de Albornoz. ${ }^{77}$ Medio siglo después de esos sucesos, la encomienda de Malli y Yumansuma fue otorgada a don Felipe García de Valdés. ${ }^{78}$

Otras menciones sobre los Malli y el distrito homónimo en Andalgalá pudieron ser reconocidas para momentos posteriores, como en una venta de tierras alrededor del pueblo indígena de Malle —en la jurisdicción de Londres - que hizo Manuel Marcelo de Olea a los hermanos Alonso y Juan de Nieva y Castillo en el año $1695,{ }^{79}$ y en un pleito entre Juan Cristóbal de Retamoso contra indios, del año 1746, por la posesión de tierras en Andalgalá que fueron de los indios Malli. ${ }^{80}$ Destaca sobre todo un extracto del Auto del teniente de gobernador Nieva y Castilla (1716), ante solicitud del obispo del Tucumán Alonso de Pozo y Silva, motivada por el traslado de la jurisdicción política de Londres a la ciudad de San Fernando del Valle de Catamarca. En este documento relativo a la demarcación de la jurisdicción eclesiástica especifica de Catamarca y sus pueblos puede leerse lo siguiente:

desde la punta y aguada de Moreno el carril que viene por el llano y falda de la sierra incluyendo sus poblaciones y dando vuelta por Alijilán hasta la cumbre de Paquilingasta y de ahí arriba hasta el Alto de Colpes pueblo antiguo que fue de los indios de Andrés de Ahumada por dicho alto hasta donde entra el río Singuil para Escaba y sale el camino que va al Pucará hasta donde topa con la jurisdicción en Pomán es el pueblo viejo de los indios Mallis, que está cerca del pueblo de Aconquija jurisdicción de Tucumán y pasando del valle de Londres en que se incluyen Andalgalá y otros muchos pueblos. ${ }^{81}$

77 «Expediente de Confirmación de Encomienda de Mallenge e Iumanjuna en San Miguel de Tucumán al capitán Juan de Ceballos Morales. Resuelto» (Sosa de Alippi 2007: 79).

78 «Expediente de Confirmación de Encomienda de Mallí y Yumansuma en Tucumán a D. Felipe García de Valdés. Resuelto» (Sosa de Alippi 2007: 143-144).

${ }^{79}$ Lizondo Borda 1936-1949, II: 217-220.

${ }^{80}$ Balesta, Zagorodny y Flores 2006.

${ }^{81}$ Brizuela del Moral y Acuña 2002: 10. 
Deben resaltarse aquí la confirmación de los Malli como antiguos habitantes del «Pucará» y la aseveración de que ese Pucará se encontraba muy cerca de Aconquija.

Hasta esta instancia del trabajo fueron presentados y analizados los valiosos resultados alcanzados en las búsquedas de referencias históricas sobre el Pucará de Aconquija y los relativos a la reconstrucción del derrotero histórico de sus posibles habitantes, los Malle/Malli. Recordando lo dicho por el arqueólogo González a comienzos de década de 1980 sobre la carencia de datos históricos sobre el Pucará, los resultados que aquí se presentan nos advierten sobre la inconveniencia de formular apresuradas conclusiones en este tipo de investigaciones.

\section{DISCUSIÓN Y CONCLUSIONES}

En ciertos pasajes de documentos históricos de los siglos XVI y XVII pueden reconocerse indicaciones que relacionan directamente algunas fortalezas con los Incas (e.g. "pucará/fuerte/guarnición del ynga/inga»). Para el NOA se pudo registrar, por ejemplo, un testimonio fechado en el año 1588 que versa sobre los procesos de pacificación de los valles Calchaquíes por parte de don Juan Ramírez de Velasco. En un apartado de esas memorias, don Luis de Hoyos comentaba: «salieron al camino rreal ocho o diez yndios con su cacique de paz y dieron en señal della maiz e yerua e mas adelante asimismo en otro asiento e pueblo de yndios llamado angastao donde esta un fuerte del ynga vinieron a su señoría otros caciques de paz». ${ }^{82}$ Por otra parte, en la región de Cuyo, se señalaba: «En el asiento y tierras del Azequion Junto aun serrillo q parece aver sido fuerte del Inga y de vn manantial q alli junto esta». ${ }^{83}$ En otras provincias del Tawantinsuyu se evocaba; "unas tierras al pie del pucara del ynga» que estuviera localizado en cercanías al poblado de San Antonio de Carangue,

${ }^{82}$ Levillier 1920: 244. La mención de "angastao" en esa cita corresponde a la actual localidad de Angastaco, departamento San Carlos, provincia de Salta. En esta localidad efectivamente se encuentra localizada una fortaleza inca (Cremonte y Williams 2007: 230).

${ }^{83}$ Otorgamiento de mercedes reales a Gabriel de Urquizo, encomendero de la zona, en el año 1617 (Micheli 1996: 137). 
Ecuador. ${ }^{84}$ En Chile, valle de Rancagua, se identificó una referencia de 1611: «y los dichos testigos fueron siguiendo la dicha acequia antigua hasta dar al fuerte del ynga questá en el camino que va a Malloa y viene a este tambo y ba corriendo el valle abajo». ${ }^{85}$ Por último, al sur de la República de Bolivia, un indígena llamado Asto rememoraba: «vio en el valle de Tarixa en Nesquila [Esquile] que es un pueblo donde estaban a la guarnición del Inca para contra los chiriguanes». ${ }^{86}$

La localización de esas fortalezas «del Inga» y de sus habitantes es de particular importancia para los interesados en analizar aspectos específicos sobre la expansión territorial del Tawantinsuyu. Precisamente, para esta investigación, se recurrió de manera complementaria a datos provenientes tanto de estudios arqueológicos como etnohistóricos.

Por un lado, los resultados obtenidos en los estudios arqueológicos permiten discutir las hipótesis formuladas previamente por otros investigadores sobre la funcionalidad de este sitio y el marco de ocupación temporal. Igualmente, otras nuevas evidencias generan otras perspectivas sobre las posibles funciones del Pucará que no habían sido claramente advertidas anteriormente.

En primera instancia, nuestros análisis señalan un componente exclusivamente incaico de ocupación en el Pucará de Aconquija, tal como queda reflejado en la coherencia formal de la arquitectura imperial en las provincias, los restos materiales muebles registrados en las excavaciones y en recolecciones superficiales, y las dos dataciones radiocarbónicas. Sobre este último aspecto, si bien reconocemos que aún es necesario contar con otros fechados para conformar un marco de referencia aún más completo, las calibraciones efectuadas en las dataciones disponibles presentan una marcada concordancia en la ocupación de ambos sectores del sitio y se sitúan exclusivamente dentro del rango de dominio inca en la región. Además, esos fechados son concurrentes con las fechas obtenidas en otros asentamientos inca del bolsón de Andalgalá. Este marco cronológico de

\footnotetext{
${ }^{84}$ Caillavet 1983: 7.

${ }^{85}$ Planella y Stehberg 1994.

${ }^{86}$ Citado en Oliveto 2011: 468.
} 
ocupación disponible permite también discutir las propuestas de otros investigadores, con las reservas del caso. Según González, «La fortaleza debió ser construida a comienzos del año 1500 de nuestra era, y quizás nunca se terminó de construir». ${ }^{87}$ A la par, Rodolfo Raffino dio a entender que el Pucará de Aconquija pudo haberse comenzado a edificar en ańos próximos a la caída del Cusco, en 1532; por lo tanto, «Incluso alguno de ellos no llegaron a completar su construcción, como sucedido con el pukará de Aconquija o Fuerte de Andalgalá, una de las instalaciones más importantes del NOA». ${ }^{88}$ Sin embargo, las dos fechas calibradas obtenidas en los pisos de ocupación del Pucará resultan ser inferiores a las fechas de ocupación que sostuvieran las hipótesis de González y Raffino.

Por otra parte, hipótesis previas sostenían que el Pucará no fue ocupado de forma permanente, ya que los grupos encargados de su cuidado vivían en asentamientos cercanos. Sin embargo, los registros materiales obtenidos en nuestras excavaciones de numerosos recintos del sitio las contradicen, ya que sustentan la ocupación efectiva del sitio por un tiempo prolongado y la realización de múltiples actividades domésticas y reuniones sociales como agasajos. Aquí es importante seńalar que ninguno de los sitios registrados en prospecciones por áreas aledañas al Pucará pudo haber albergado grandes contingentes de personas.

Otras hipótesis relacionadas a la funcionalidad del Pucará de Aconquija acentuaban que su única misión fue la defensa militar de ese territorio. Esas propuestas se sustentaron básicamente en indicadores relativos a su ubicación - en lo alto de un cerro y de difícil acceso- y en rasgos arquitectónicos de evidente connotación militar-defensiva. Más allá de esos indicadores superficiales, en nuestras excavaciones no registramos cuantiosas y variadas evidencias que puedan relacionarse a una preocupación y preparación para conflictos armados. Tampoco se registró en el Pucará, a diferencia de lo observado en otras fortalezas incas ubicadas en las fronteras, apilamientos de piedras arrojadizas en tramos de las murallas y en el interior de los torreones. Debemos notar que lo escaso

\footnotetext{
${ }^{87}$ González 2000: 160.

${ }^{88}$ Raffino 2007: 314
} 
de esos elementos defensivos no se debería necesariamente a una falta de preocupación por la defensa del sitio: tal vez los elementos líticos utilizados como armas, por ser fácilmente transportables y por su valor intrínseco, pudieron haber sido cargados por los habitantes del Pucará al momento de abandonar el sitio. Debe señalarse también que los sitios de momentos incas registrados en prospecciones por áreas aledañas al Pucará no presentan rasgos espaciales y arquitectónicos que distingan fines defensivos. Todos ellos se encuentran emplazados en ambientes topográficos de cómodo acceso, ${ }^{89}$ cercanos al curso de agua permanente (río Pucará), no cuentan con rasgos arquitectónicos defensivos y se ubican a corta distancia del Pucará. Nos inclinamos a pensar que cada uno de esos asentamientos de reducidas dimensiones y con escasos recintos habitacionales pudo haber estado articulado complementariamente al Pucará. Este último habría cumplido el papel de centro principal local como parte de un sistema orientado a la obtención de recursos alimenticios para las personas que vivían en el Pucará.

Algunos investigadores sostuvieron anteriormente que el interés incaico en la región del bolsón de Andalgalá se basó en la obtención de mano de obra local, el impulso de la metalurgia y la necesidad de extender sus dominios efectivos. ${ }^{90}$ Para asegurar esos objetivos, los Incas promovieron, desde 1420 aproximadamente, un conjunto de actividades artesanales, agrícolas y mineras en áreas productivas supervisadas desde centros administrativos y controladas por fortalezas estratégicamente localizadas. Estos asentamientos fueron delegados a poblaciones - colonos_leales. En este contexto, el Pucará de Aconquija fue emplazado en una «frontera externa» de acuerdo con la propuesta de Lorandi, en estrecha cercanía espacial con ambientes de yungas habitados por poblaciones que las fuentes históricas describieron como nómades y peligrosas. En consonancia con esas propuestas, pensamos que muy probablemente una de las funciones del Pucará haya sido defender esa posible conflictiva «frontera

${ }^{89}$ Esos sitios fueron registrados en mesadas relativamente amplias que se desprenden de filos que se originan en los cerros. Se encuentran también relativamente cerca a fuentes de agua permanente y, por su ubicación espacial, pudieron ser visibles entre ellos.

${ }^{90}$ Véase, por ejemplo, Williams y D'Altroy 1998; Williams 2000; y Lorandi 1988. 
externa» por medio de grupos trasladados desde Santiago del Estero y algunas poblaciones Diaguitas movilizadas desde el oeste de Catamarca.

Pero más allá de estas coincidencias con las propuestas de Lorandi, nos hemos comenzado a preguntar: ¿pudo el Pucará de Aconquija haber sido también un baluarte defensivo contra posibles revueltas-rebeliones de algunas poblaciones Diaguitas? Algunos elementos de análisis así parecen sugerirlo: indudablemente el Pucará fue planificado de acuerdo con la consideración de una seria amenaza de ataques armados a gran escala. A las dificultades planteadas a los atacantes por el dificultoso y escabroso acceso, se adicionó la sofisticación arquitectónica bélica reflejada en el portentoso despliegue de extensas murallas y otros implementos arquitectónicos de innegable connotación defensiva (como banquetas, parapetos y saeteras) desplegados en puntos críticos. De acuerdo con esto, a diferencia de la amenaza que podría representar los ataques a una escala mucho menor y de tipo furtivo (por ejemplo, de los Lules nómades), pensamos que las variables arquitectónicas defensivas del Pucará debieron ser pensadas e implementadas contra varios frentes de ataque. Las amenazas a enfrentar posiblemente serían fuerzas agresoras compuestas por numerosos guerreros con un alto grado de adiestramiento en asaltos a fortalezas y con un variado repertorio armamentístico.

En ese sentido, pensamos que, por tantas preocupaciones defensivas implementadas en el sitio y por su ubicación en el terreno, el Pucará fue ideado para resistir asedios prolongados. ${ }^{91}$ Su ubicación estratégica, además, a unos pocos kilómetros de una de las áreas nucleares Diaguita, nos permite también pensar que, en caso de producirse una rebelión de estos últimos, las poblaciones aliadas a los incas asentadas en esas regiones pudieron haber encontrado refugio en el mismo Pucará de Aconquija. No debemos soslayar que algunas fuentes históricas señalaron que numerosas poblaciones Diaguitas ofrecieron feroz resistencia a la conquista incaica — como también a las posteriores campañas de

${ }^{91}$ En caso de haberse producido un asedio al Pucará, sus habitantes podían haber contado con recursos alimenticios almacenados en las qollqas y, fundamentalmente, con agua proveniente de una vertiente pequeña localizada a muy corta distancia de las murallas (Aguada de Las Chilcas); esta vertiente actualmente está seca (Lange 1892: 10). 
los españoles - y que, aun bajo su control, retacearon su mano de obra para el Tawantinsuyu. ${ }^{92}$ Nuestra hipótesis del Pucará como fortificación defensiva contra revueltas locales puede insertarse apropiadamente dentro de la propuesta de Lorandi de una conflictiva "frontera interna» de los Incas en la región.

Para complejizar nuestra perspectiva sobre las funciones del Pucará de Aconquija, las investigaciones en desarrollo destacan una marcada relevancia sagrada-ceremonial admitida por los registros de una wak'a que sobresale nítidamente en el interior del sitio y de la wank'a asociada al tramo del qhapac ñan. Estas evidencias señalan, sin lugar a dudas, que en el sitio también se realizaron otras actividades distintas o complementarias a las estrictamente militares-defensivas. Desde un marco general, la consideración de analizar en profundidad la articulación de factores militares-defensivos y sagrados-ceremoniales en sitios del Tawantinsuyu ya había sido reclamada por otros investigadores. ${ }^{93}$ Las excavaciones a efectuarse en breve en la wak'a y wank'a aportarán datos clarificadores para acrecentar nuestro conocimiento general sobre la relación entre la guerra y los ritos-ceremonias en la cosmología incaica.

Por otra parte, en este trabajo se puso a prueba la hipótesis que relacionaba al Pucará de Aconquija con el «Pucará que llaman del Inga» de la merced del capitán Sebastián de Loria. Diferentes líneas de investigación permitieron corroborar ese supuesto. El análisis de esa merced nos aportó pistas sobre los habitantes del Pucará, los Malle/Malli. La recopilación e investigación de otras fuentes permitieron reconstruir su derrotero histórico, principalmente a partir de los primeros años del siglo XVII.

En primera instancia, varias fuentes elaboradas durante las primeras décadas del siglo XVII, inclusive anteriores a la merced del capitán Loria, refieren a la ocupación de los sectores serranos del sur del valle de Aconquija por las poblaciones Diaguitas. Entre esas poblaciones

${ }^{92}$ Lorandi 1988: 241-243.

93 Véase, por ejemplo, Arkush y Stanish 2005; y Hyslop 1990: 148. En Chile se comenzaron a analizar algunas fortalezas incaicas desde una perspectiva que recalca la importancia de los componentes simbólicos-rituales en lo que denominan "guacas-fortalezas»; véase Stehberg y Sotomayor 1999. 
se encontraba una unidad poblacional con identidad diferencial «Malle», que en el tiempo fue referida con una variada etnonimia. En los recuentos del padre Lozano sobre la travesía evangelizadora de Boroa y Darío por el valle de Aconquija, se delimitó a los Malle como parte de las poblaciones Diaguitas, aunque no mencionó específicamente a las poblaciones Lules-Juries movilizadas por los Incas. Sin embargo, sobre los Lules se obtienen referencias en las disputas legales entre Espinoza y Villadiego por los pueblos de encomiendas de Mallempes (Malincho) y Tactao (Tactaxita). Si aceptamos que Mallempes es un sinónimo del pueblo de Malle encomendado a Juan de Espinoza en 1607, es sugerente que lo denominado como Mallempes hubo de pertenecer (¿indistintamente?) a lo «Diaguita» y a lo «Lule».

Desafortunadamente, en los análisis de las fuentes históricas no obtuvimos otros datos que permitieran desentrañar más claramente la pertenencia étnica de los Malle y la confirmación de su participación activa en el entramado político incaico de la región. Sin embargo, de acuerdo con nuestro análisis general de esos textos históricos, consideramos que no quedan dudas sobre los Malle como una población mitmaqkuna asentada en ese «Pucará del Inga».

¿Qué nos aporta la arqueología para este dilema de investigación sobre identidad étnica? Por un lado, resultan indicativos los registros en las recolecciones superficiales y excavaciones efectuadas en el Pucará de estilos cerámicos tanto de Lules sedentarios (Famabalasto negro sobre rojo y Yocavil) y, en menor medida, de Diaguitas (e.g. Santamariano). La implementación de variadas técnicas arquitectónicas aporta indicios relativos a diferentes grupos étnicos cumplimentando prestaciones en el Pucará. Esto se determinó a partir de los registros de tipos de cimientos en las paredes de los recintos, los tramos de las murallas elaborados de maneras disimiles y la colocación intencional de piedras de colores contrastantes en algunas de las paredes. Como ya fue puntualizado, algunas de estas pautas arquitectónicas sugieren la participación de grupos Diaguitas del valle de Santa María.

Ante todos estos indicadores, sugerimos que el Pucará fue ocupado por poblaciones aliadas y leales a los Incas: Juries y Diaguitas; así, llegaron 
a constituir un enclave multiétnico, tal como fue registrado en otras fortalezas incas. Dentro de un contexto de investigación más amplio, este mosaico multiétnico originado por las políticas y estrategias incas fue establecido en prácticamente toda la región del bolsón de Andalgalá. ${ }^{44}$ Dentro de este marco general de políticas y estrategias incaicas, los documentos históricos no aportaron mayores precisiones sobre el valle de Aconquija como una frontera «caliente» para la seguridad del Tawantinsuyu que necesitaba ser defendida de los Lules nómades del este, como lo sugieren las hipótesis planteadas por otros investigadores. Resulta particularmente llamativo que, en los documentos históricos disponibles a partir de las primeras décadas del siglo XVII en adelante, no se hicieran menciones sobre Lules nómades aprovechando las circunstancias de confusión y reordenamiento tras el derrumbe del dominio inca por la invasión española al Perú. Se debe considerar que esto último implicó la desarticulación de los sistemas defensivos centralizados en el bolsón de Andalgalá en el que el Pucará de Aconquija debió haber tenido un papel protagónico central.

En esta instancia del análisis, surge una pregunta relevante: ¿qué sucedió con el Pucará de Aconquija y sus habitantes al momento de la caída del Tawantinsuyu y durante los primeros años de la conquista española en la región? Nuestras investigaciones indican que los Malle no regresaron a su lugar de origen, sino que permanecieron en el valle de Aconquija luego de desarticulada la organización establecida por el Tawantinsuyu. Los datos obtenidos en algunas fuentes de las primeras décadas del siglo XVII señalan que los Malle sobrellevaron los drásticos cambios impuestos por el dominio colonial — procesos de traslados forzados a diversos lugares-. Posteriormente, de acuerdo con lo referido por el gobernador Albornoz, encontramos a los Malle como «mayores convocadores» en el ámbito serrano del oeste de Catamarca, donde participaban activamente en las rebeliones locales contra los espańoles. En esos textos reconocimos a don Pedro Chumay, posible cacique de los Malle y/o de los Aconquijas, y a grupos indígenas locales posiblemente asentados en el mismo Pucará

${ }^{94}$ Véanse, por ejemplo, Lorandi 1992; y Williams 2000: 69-70. 
de Aconquija o en otro sitio cercano hasta una fecha bastante tardía: primeros años de la década de 1630. Esa fecha posiblemente señalaría el fin de esa ocupación debido a las sucesivas derrotas en los aciagos sucesos de las guerras Calchaquíes.

Pese a la importancia estratégica que pudo haber tenido este asentamiento para los nativos de la zona de Aconquija-Andalgalá, pasó definitivamente al olvido luego de aquellas capitulaciones. Debo destacar, en este sentido, que en las tareas de campo efectuadas en el sitio no registramos ningún tipo de evidencia que confirmara la persistencia de su uso hasta momentos tan tardíos, aunque esta posibilidad no se descarta como resultado de futuras tareas. Finalmente, los Malle/Malli fueron inmediatamente extrañados de sus tierras y llevados a Córdoba en castigo por su participación en el alzamiento de 1632, para posteriormente ser trasladados a la localidad de Huaco (La Rioja) alrededor del año 1650. A modo de cierre, considero que el conjunto de investigaciones efectuadas al presente permitieron reconstruir en gran medida la historia del Pucará de Aconquija y de sus habitantes, tanto para momentos del dominio incaico como las para décadas posteriores, durante la colonia española. De acuerdo con el grado de avance de los trabajos desarrollados en ese sitio, se concurre positivamente en dirección de revertir un reclamo efectuado años atrás:

Algunas de las fortalezas [incas] más grandes como Incallacta en Bolivia, o la de Pucará de Andalgalá en Argentina, todavía necesitan de minuciosas investigaciones que comprendan excavaciones, estudios etnohistóricos complementarios, y reconocimientos de los patrones de asentamiento. ${ }^{95}$

Por supuesto, tal como fuera expuesto anteriormente, permanece en nuestra agenda de trabajo un conjunto de actividades que serán desarrolladas próximamente. Seguramente los resultados de esas investigaciones seguirán contribuyendo a reconstruir otros aspectos sobre este magnífico «Pucará del Inga». 


\section{BIBLIOGRAFÍA}

Acosta, José de. 1894. Historia Naturaly Moral de las Indias. Madrid: Ramón Anglés Impresor, 2 vols.

Alconini, Sonia. 2004. «The Southeastern Inka Frontier against the Chiriguanos: Structure and Dynamics of the Inka Imperial Borderlands». Latin American Antiquity. Vol. 15, núm. 4: 389-418. https://doi.org/10.2307/4141585

Arkush, Elizabeth y Charles Stanish. 2005. «Interpreting conflict in the ancient Andes: Implications for the archaeology of warfare». Current Anthropology. Vol. 46, núm. 1: 3-28. https://doi.org/10.1086/425660

Balesta, Bárbara, Nora Zagorodny y Marina Flores. 2006. «Desestructuración étnica en Catamarca prehispánica (Argentina)». Boletín de Antropología Americana. Núm. 42: 91-117.

Boixadós, Roxana. 2007-2008. «Recreando un mundo perdido. Los pueblos de indios del valle de Famatina a través de la visita de 1667 (La Rioja, gobernación de Tucumán)». Población y Sociedad. Vols. 14-15, núm. 5: 3-31.

.2008. "Caciques y mandones de Malligasta. Autoridad y memoria en un pueblo de indios de La Rioja colonia». Andes. Núm. 19: 251-278.

Boman, Eric. 1918. "Tres cartas de gobernadores del Tucumán sobre Todos los santos de la nueva rioja y sobre el gran alzamiento». Revista de la Universidad Nacional de Córdoba. Año V, vol. I, núm. XI: Núm. 1: 150-201.

Bray, Tamara. 2003. «Inka pottery as culinary equipment: Food, feasting, and gender in Imperial State design». Latin American Antiquity. Vol. 14, núm. 1: 3-28. https://doi.org/10.2307/972233

2004. «La alfarería imperial inka: una comparación Entre la cerámica estatal del área de Cuzco y la cerámica de las provincias». Chungara. Vol. 36, núm. 2: 365-374. https://dx.doi.org/10.4067/S0717-73562004000200010

2015. «Andean Wak'as and Alternative Configurations of Persons, Power, and Things». En Bray, Tamara (ed.). The Archaeology of Wak'as Explorations of the Sacred in the Pre-Columbian Andes. Boulder: University Press of Colorado, 3-22. https://doi.org/10.5876/9781607323181.c001

Brizuela del Moral, Félix. 2003. Historia de las Mercedes de tierras en Catamarca. Siglos XVI al XIX. Catamarca: Universidad Nacional de Catamarca-CENEDIT. Brizuela del Moral, Félix y María Acuña. 2002. La jurisdicción territorial de Catamarca. Trabajo presentado en el Congreso Regional de Ciencia y Tecnología del NOA, Universidad Nacional de Catamarca.

Bruch, Carlos. 1913. «Exploraciones arqueológicas en las provincias de Tucumán y Catamarca». Revista del Museo de La Plata. Vol. 19, núm. 1: 1-202.

Cabrera, Pablo. 1910. Ensayos sobre entología argentina. Los Lules. Córdoba: Universidad Nacional de Córdoba. 
1926. Tesoros del pasado Argentino. Estudios históricos y geográficos del Tucumán. Córdoba: Universidad Nacional de Córdova.

Caillavet, Chantal. 1983. «Toponimia histórica, arqueología y formas prehispánicas de agricultura en la región de Otavalo-Ecuador». Bulletin de l'Institut Français d'Études Andines. Vol. XII, núms. 3-4: 1-21.

. 1985. «La adaptación de la dominación incaica a las sociedades autóctonas de la frontera septentrional del Imperio: (Territorio Otavalo-Ecuador)». Revista Andina. Vol. 3, núm. 2: 403-423.

Calderari, Milena y Verónica Williams. 1991. «Re-evaluación de los estilos cerámicos del noroeste argentino». Comechingonia. Año 9, número especial: El Imperio Inka. Actualización y perspectivas y registros arqueológicos y etnohistóricos, vol. 2: 75-95.

Cieza de León, Pedro. 2005. Guerras civiles del Perú. Tomo segundo: Guerra de Chupas. Edición digital. Alicante: Biblioteca Virtual Miguel de Cervantes. http://www.cervantesvirtual.com/obra/guerras-civiles-del-perutomo-segundo-guerra-de-chupas--0/

Cremonte, María Beatriz y María Garay de Fumagalli. 2013. «Diferentes modalidades de estructuración de la frontera suroriental Inka en el actual territorio de Jujuy». En Williams, Verónica y María Beatriz Cremonte (comps.). Al borde del imperio. Paisajes sociales, materialidad y memoria en áreas periféricas del noroeste argentino. Buenos Aires: Sociedad Argentina de Antropología, 57-74.

Cremonte, María y Verónica Williams. 2007. «La construcción social del paisaje durante la dominación Inka en el Noroeste Argentino». En Nielsen, Axel E., y otros (comps), Procesos sociales prehispánicos en el sur andino: la vivienda, la comunidad y el territorio. Córdoba: Editorial Brujas, 207-236.

D’Altroy, Terence. 2003. Los Incas. Barcelona: Editorial Ariel.

De la Vega Díaz, Dardo. 1994. Toponimia Riojana. La Rioja: Ed. Canguro.

Del Techo, Nicolás. 1897. Historia de la provincia de Paraguay de la Compañía de Jesús. Madrid: Librería y Casa Editorial A. Uribe \& Cia.

Dean, Carolyn. 2010. A culture of stone. Inka perspectives on rock. Durham y Londres: Duke University Press. https://doi.org/10.1215/9780822393177

Dietler, Michael y Brian Hayden. 2001. "Digesting the feast: good to eat, good to drink, good to think». En Dietler, Michael y Brian Hayden (eds.). Feast. Archaeological and ethnographic perspectives on food, politics and power. Washington, D.C.: Smithsonian Institute Press, 1-20.

Dillehay, Tom y Patricia Netherly (comps.). 1998. La frontera del imperio Inca. Oxford: British Archeological Reports.

Gianfrancisco, M. Soledad. 2014. «Repensando los sitios Alamito. Nuevos aportes a la arqueología de Campo de Pucará». Arqueología. Vol. 20, núm. 2: 157-182. González, Alberto. 1982. "Las provincias inca del antiguo Tucumán». Revista del Museo Nacional. Núm. XLVI: 317-380. 
2000. Tiestos dispersos. Voluntad y azar en la vida de un arqueólogo. Buenos Aires: Emecé Editores.

González Alberto y Víctor Núñez Regueiro. 1958-1959. «Apuntes preliminares sobre la arqueología del Campo del Pucará y alrededores (Dto. Andalgalá, Pcia. de Catamarca)». Anales de Arqueología y Etnología. Vols. 14-15: 115-162. Guzmán, Gaspar. 2010. Historia Colonial de Catamarca. Catamarca: Editorial Sarquis.

Hogg, Alan y otros. 2013. «SHCal13 Southern Hemisphere Calibration, 0-50,000 Years cal BP». Radiocarbon. Vol. 55, núm. 4: 1889-1903. https://doi. org/10.2458/azu_js_rc.55.16783

Hyslop, John. 1988. "Las fronteras estatales extremas del Tawantinsuyu». En Dillehay, Tom y Patricia Netherly (eds.). La Frontera del Estado Inca. Oxford: British Archaeological Reports, 35-57. . 1990. Inca settlement planning, Austin: University of Texas Press.

Jennings, Justin. 2004. «La Chichera y el Patrón: Chicha and the energetics of feasting in the prehistoric Andes». Archaeological Papers of the American Anthropological Association. Vol. 14: 241-259. https://doi.org/10.1525/ap3a.2004.14.241

Kaulicke, Peter. 2005. «Las fiestas y sus residuos: algunas reflexiones finales». Boletín de Arqueología PUCP. Vol. 9: 387-402.

Kriscautzky, Néstor. 2002-2004. «Pucará de Aconquija, incaico, catamarqueño, y monumento histórico nacional. ¿Lo verán nuestros hijos?». Boletín Oficial de la Junta de Estudios Históricos de Catamarca. Núm. 14: 161-178.

Lafone Quevedo, Samuel. 1888. Londres y Catamarca. Buenos Aires: Imprenta de Mayo.

1892. "Catálogo descriptivo e ilustrado de las Huacas de Chañar-Yaco». Revista del Museo de La Plata. Vol. 3: 35-63.

. 1898. Tesoro de Catamarqueñismos: Nombres de lugar y apellidos indios con etimologias y eslabones aislados de la lengua canana. Buenos Aires: Imprenta de Pablo Coni e hijos.

Lange, Gunardo. 1892. «Las ruinas de la fortaleza del pucará». Anales del Museo de La Plata. Sección de Arqueología. Núm. 3: 3-16.

Larrouy, Antonio. 1941. «Aconquija». Boletín de la Junta de Estudios Históricos de Catamarca. Núm 1: 47-51.

.2004. Autonomía Catamarqueña. Homenaje en su primer centenario 18211921. Catamarca: Editorial Sarquis.

Levillier, Roberto. 1920. Gobernación del Tucumán, Papeles de los Gobernadores en el Siglo XVI, Documentos del Archivo de Indias. Madrid: Imprenta de Juan Pueyo. Lizárraga, Reginaldo de. 1916. Descripción Colonial. Buenos Aires: Librería La Facultad, 2 vols. 
Lizondo Borda, Manuel. 1936-1949. Documentos coloniales relativos a San Miguel de Tucumán y a la Gobernación de Tucumán. Tucumán: Junta Conservadora del Archivo Histórico de Tucumán, 6 vols.

Lorandi, Ana. 1980. «La frontera oriental del Tawantinsuyu.: El Umasuyu y el Tucumán. Una hipótesis de trabajo». Relaciones de la Sociedad Argentina de Antropología. Vol. 14, núm. 1: 147-164.

. 1983. «Mitayos y mitmaqkunas en el Tawantinsuyu meridional». Histórica. Vol. 7, núm. 1: 3-50.

. 1988. «Diaguitas y el Tawantinsuyu: una hipótesis de conflicto». En Dillehay, Tom y Patricia Netherly (eds.). La Frontera del Estado Inca. Oxford: British Archaeological Reports, 235-259.

. 1992. «El mestizaje interétnico en el noroeste argentino». Senri Ethnological Studies. Núm. 33: 133-166.

Lorandi, Ana y Roxana Boixadós. 1987-1988. «Etnohistoria de los Valles Calchaquíes en los siglos XVI y XVII». Runa. Vols. 17-18: 263-420.

Lozano, Pedro. 1754-1755. Historia de la Compañia de Jesús de la Provincia de Paraguay. Tomo II. Madrid: Imprenta de la viuda de Manuel Fernández, 2 vols.

Meyers, Albert. 1975. "Algunos problemas en la clasificación del estilo incaico». Pumapunku. Vol. 8: 7-25.

Micheli, Catalina. 1996. Realidad socioeconómica de los indígenas de San Juan en el siglo XVII. San Juan: Instituto de Investigaciones Arqueológicas y Museo.

Nastri, Javier. 2001. «La arquitectura aborigen de la piedra y la montaña (noroeste argentino, siglos XI a XVII)». Anales del Museo de América. Núm. 9: 141-163.

Niles, Susan. 1987. Callachaca. Style and status in an Inca commuity. Iowa City: University of Iowa Press.

Núnez Regueiro, Víctor. 1974. «Conceptos instrumentales y marco teórico en relación al análisis del desarrollo cultural del noroeste argentino». Revista del Instituto de Antropología. Núm. 5: 169-190.

. 1998. Arqueología, historia y antropología de los sitios Alamito. Tucumán: Ediciones Interdea.

Oliveto, Lía Guillermina. 2011. «De mitmaqkuna incaicos en Tarija a reducidos en La Plata. Tras las huellas de los moyos moyos y su derrotero colonial». Anuario del Archivo y Bibliotecas Nacionales de Bolivia. Núm 17: 463-490.

Orgaz, Martin, Néstor Kriscautzky y Sergio Caletti. 2007. «Infraestructura vial Inka en el Departamento de Andalgalá-Catamarca-Argentina». En Actas de Resúmenes del XVII Congreso Nacional de Arqueología Argentina. Jujuy: Universidad Nacional de Jujuy, t. I, 519-524.

Pärssinen, Martti y Ari Siiriäinen. 2003. Andes Orientales y Amazonia Occidental. Ensayos entre la Historia y la Arqueología de Bolivia, Brasil y Perú. La Paz: Producciones CIMA. 
Pérez Sáez, Vicente Juan y María Fanny Osán de Pérez Sáez. 1997-1998. El Español de la Argentina. Documentos para su Historia. Salta: Universidad Nacional de Salta, 2 vols.

Planella, María Teresa y Rubén Stehberg. 1994. «Etnohistoria y arqueología en el estudio de la fortaleza de Cerro Grande de la Compañía». Chungara. Vol. 26, núm. 1: 65-78.

Raffino, Rodolfo. 2007. Poblaciones indígenas de la Argentina. Buenos Aires: Emecé Editores.

Raffino, Rodolfo y Rubén Stehberg. 1999. «Tawantinsuyu: The frontiers of the Inca Empire». En Politis, Gustavo y Benjamin Alberti (eds.). Archaeology in Latin America. London: Routledge, 167-181.

Ramsey, Christopher Bronk. 2009. «Bayesian analysis of radiocarbon dates». Radiocarbon. Vol. 51, núm. 1:337-360. https://doi.org/10.1017/S0033822200033865

Ratto, Norma. 2000. Relevamiento y diagnóstico del patrimonio arqueológico de la provincia de Catamarca. Informe final y Software interactivo presentado al Consejo Federal de Inversiones (CFI). Ms.

Reynoso, Alejandra. 2009. «El color y el fuego: Excavaciones en la plaza de la cumbre de rincón Chico». Comechingonia. Núm. 12: 75-90.

Rowe, John H. 1985. «Probanza de los incas nietos de los conquistadores». Histórica. Vol. 9, núm. 2: 193-245.

Schaposchnik, Ana. 1997. «Aliados y parientes. Los diaguitas rebeldes de Catamarca durante el gran alzamiento». En Lorandi, Ana (comp.). El Tucumán colonial y Charcas. Buenos Aires: Universidad Nacional de Buenos Aires, t. I, 309-340.

Schjellerup, Inge. 1998. «Aspects of the Inca frontier in Chachapoyas». Tawantinsuyu. Núm. 5: 160-165.

Sosa de Alippi, Alicia. 2007. Registro de Encomiendas en Territorio Argentino. Siglo XVII. Expedientes existentes en el Archivo de Indias. Córdoba: Centro de Estudios Genealógicos y Heráldicos de Córdoba.

Stehberg, Rubén y Gonzalo Sotomayor. 1999. "Cabis, guacas-fortalezas y el control incaico del valle de Aconcagua». Estudios Atacameños. Núm. 18: 237-248. https://doi.org/10.22199/s07181043.1999.0018.00017

Tarragó, Myriam. 2000. «Chacras y Pukara. Desarrollos sociales tardíos». En Tarragó, Myriam (dir.). Los pueblos originarios y la conquista. Nueva Historia Argentina. Buenos Aires: Editorial Sudamericana, t. I, 257-300.

Tarragó, Myriam y Luis González. 2004. «Arquitectura social y ceremonial en Yocavil, Catamarca». Relaciones de la Sociedad Argentina de Antropología. Vol. 29: 297-315.

Tschudi, Johann von. 1966. «Viaje por las Cordilleras de los Andes de Sudamérica, de Córdoba a Cobija, en el año 1858». Boletín de la Academia Nacional de Ciencias. Vol. 45: 323-406. 
Ward, Graeme K. y Susan R. Wilson. 1978. «Procedures for comparing and combining radiocarbon age determinations: A critique». Archaeometry. Vol. 20, núm. 1: 19-31.

Williams, Verónica. 2000. «El imperio Inka en la provincia de Catamarca». Intersecciones en Antropología. Ańo 1, núm. 1: 55-78.

Williams, Verónica y Terence D’Altroy. 1998. «El sur del Tawantinsuyu. Un dominio selectivamente intensivo». Tawantinsuyu. Núm. 5: 170-178.

Williams, Verónica y María Beatriz Cremonte. 1992-1993. «¿Mitmaqkuna o circulación de bienes? Indicadores de la producción cerámica como identificadores étnicos. Un caso de estudio en el Noroeste Argentino». Avances en Arqueología. Vol. 2: 9-21.

Zanolli, Carlos. 2003. "Los Chichas como mitimaes del Inca». Relaciones de la Sociedad Argentina de Antropología. Vol. 28: 45-60.

Recepción: 28/IV/2016 Aceptación: 20/VI/2016 